\title{
The nested enzyme-within-enterocyte (NEWE) turnover model for predicting dynamic drug and disease effects on the gut wall
}

DOI:

10.1016/j.ejps.2019.02.017

\section{Document Version}

Accepted author manuscript

Link to publication record in Manchester Research Explorer

Citation for published version (APA):

Darwich, A. S., Burt, H. J., \& Rostami-hodjegan, A. (2019). The nested enzyme-within-enterocyte (NEWE) turnover model for predicting dynamic drug and disease effects on the gut wall. European Journal of Pharmaceutical Sciences. https://doi.org/10.1016/j.ejps.2019.02.017

\section{Published in:}

European Journal of Pharmaceutical Sciences

\section{Citing this paper}

Please note that where the full-text provided on Manchester Research Explorer is the Author Accepted Manuscript or Proof version this may differ from the final Published version. If citing, it is advised that you check and use the publisher's definitive version.

\section{General rights}

Copyright and moral rights for the publications made accessible in the Research Explorer are retained by the authors and/or other copyright owners and it is a condition of accessing publications that users recognise and abide by the legal requirements associated with these rights.

\section{Takedown policy}

If you believe that this document breaches copyright please refer to the University of Manchester's Takedown Procedures [http://man.ac.uk/04Y6Bo] or contact uml.scholarlycommunications@manchester.ac.uk providing relevant details, so we can investigate your claim.

\section{OPEN ACCESS}




\section{Accepted Manuscript}

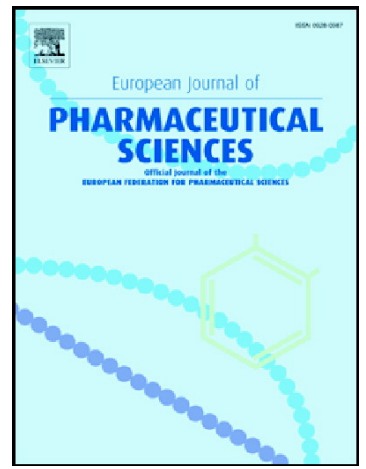

Adam S. Darwich, Howard J. Burt, Amin Rostami-Hodjegan

PII: $\quad$ S0928-0987(19)30070-3

DOI: $\quad$ https://doi.org/10.1016/j.ejps.2019.02.017

Reference: $\quad$ PHASCI 4847

To appear in: $\quad$ European Journal of Pharmaceutical Sciences

Received date: $\quad 5$ June 2018

Revised date: $\quad 11$ February 2019

Accepted date: $\quad 12$ February 2019

Please cite this article as: A.S. Darwich, H.J. Burt and A. Rostami-Hodjegan, The nested enzyme-within-enterocyte (NEWE) turnover model for predicting dynamic drug and disease effects on the gut wall, European Journal of Pharmaceutical Sciences, https://doi.org/10.1016/j.ejps.2019.02.017

This is a PDF file of an unedited manuscript that has been accepted for publication. As a service to our customers we are providing this early version of the manuscript. The manuscript will undergo copyediting, typesetting, and review of the resulting proof before it is published in its final form. Please note that during the production process errors may be discovered which could affect the content, and all legal disclaimers that apply to the journal pertain. 


\section{The nested enzyme-within-enterocyte (NEWE) turnover model for}

\section{predicting dynamic drug and disease effects on the gut wall}

Adam S. Darwich ${ }^{1, *}$, Howard J. Burt ${ }^{2}$, Amin Rostami-Hodjegan ${ }^{1,2}$

${ }^{1}$ Centre for Applied Pharmacokinetic Research, School of Health Sciences, The University of Manchester, Manchester, United Kingdom.

${ }^{2}$ Certara UK Ltd., Sheffield, United Kingdom.

*Corresponding author:

Adam S. Darwich

Room 3.123, Stopford Building,

University of Manchester,

Oxford Road,

Manchester M13 9PT,

Greater Manchester,

United Kingdom

Tel: $+44(0) 161-2752399$

Fax: $+44(0) 161-2758349$

Email:adam.darwich@manchester.ac.uk 


\begin{abstract}
Physiologically-based pharmacokinetic (PBPK) models provide a framework for in vitro-in vivo extrapolation of metabolic drug clearance. Many of the concepts in PBPK can have consequential impact on more mechanistic systems pharmacology models. In the gut wall, turnover of enzymes and enterocytes are typically lumped into one rate constant that describes the time dependent enzyme activity. This assumption may influence predictability of any sustained and dynamic effects such as mechanism-based inhibition (MBI), particularly when considering translation from healthy to gut disease.
\end{abstract}

A novel multi-level systems PBPK model was developed. This model comprised a 'nested enzyme-within enterocyte' (NEWE) turnover model to describe levels of drug-metabolising enzymes. The ability of the model to predict gut metabolism following MBI and gut disease was investigated and compared to the conventional modelling approach.

For MBI, the default NEWE model performed comparably to the conventional model. However, when drug-specific spatial crypt-villous absorption was considered, up to approximately $50 \%$ lower impact of MBI was simulated for substrates highly metabolised by cytochrome P450 (CYP) 3A4, interacting with potent inhibitors. Further, the model showed potential in predicting the disease effect of gastrointestinal mucositis and untreated coeliac disease when compared to indirect clinical pharmacokinetic parameters.

Considering the added complexity of the NEWE model, it does not provide an attractive solution for improving upon MBI predictions in healthy. However, nesting turnover may enable extrapolation to gut disease-drug interactions. The principle detailed herein may be useful for modelling drug interactions with cellular targets where turnover is significant enough to affect this process. 


\section{Keywords:}

Physiologically-based pharmacokinetics; modeling and simulation; quantitative systems pharmacology; gut wall metabolism; turnover; special populations; drug-drug interactions.

\section{Prologue}

The mechanistic understanding of events in the gut wall following the interaction between food components and drugs has helped to delve into details of drug absorption kinetics beyond classical compartmental pharmacokinetic modelling. The contributions by Dr Harmut Derendorf and his research team over the years to this subject matter has been significant and we wish to dedicate this piece of work to honouring his research into drug absorption and understanding of the gut wall (Greenblatt and Derendorf, 2013, Butterweck et al., 2009, De Castro et al., 2007). Dr Derendorf has over the course of his career been a leader in promoting a systematic approach to clinical pharmacology from the individual patient factors and disease, to the route of administration and unbound drug concentration at the site of action. This as well as the use of pharmacokinetic/pharmacodynamics modelling to individualise dosing, understand the underlying processes and their interactions (Gonzalez et al., 2013, Gonzalez et al., 2011, Derendorf and Meibohm, 1999).

\section{Introduction}

For drugs that are mainly metabolised via cytochrome P450 3A4 (CYP3A4), the small intestine can display comparable first-pass extraction to the liver following oral administration (Thelen and Dressman, 2009). The prediction of gut wall metabolism has 
therefore been the focus of much research (Gertz et al., 2011, Gertz et al., 2010, Margolskee et al., 2017, Yang et al., 2007, Pang, 2003). Physiologically-based pharmacokinetic (PBPK) modelling and simulation $(\mathrm{M} \& \mathrm{~S})$ provides a quantitative framework for in vitro-in vivo extrapolation (IVIVE) of metabolic clearance to healthy, disease and following metabolic drug-drug interactions (DDIs) (Howgate et al., 2006, Jamei, 2016). However, the gut wall is challenging to model because of the difficulty in measuring its effects directly clinically (Kolars et al., 1991), as a consequence many challenges and assumptions remain.

A trend towards an overprediction of drug-drug interactions mediated by oral administration of mechanism-based enzyme inhibitors has been reported (Obach et al., 2007, Fahmi et al., 2009, Galetin et al., 2008, Burt et al., 2012). One contributing factor is thought to be an inaccurate description of gut wall metabolism or inhibition. In special disease patient populations, modelling of gut wall metabolism relies on phenotypic in vivo data obtained from a population sample, e.g., proteomic enzyme abundance data (Johnson et al., 2001). These data are often missing or may give an incomplete picture of the underlying mechanism that causes the observed changes (Johnson et al., 2001, Johnson et al., 2010). Both of these examples highlight the difficulty in modelling perturbations of the gut.

In theory, PBPK is apt for coupling with systems models of pharmacology, biology or disease, into multi-level systems models (Bhattacharya et al., 2012, Thiele et al., 2017). This may provide opportunities for using morphological/pathophysiological data to inform systems parameters that otherwise are not easily determined. The added level of complexity may also enable extrapolation from healthy to disease conditions and other physiological perturbations (such as MBI), sharing of information across models, and provide added certainty to complex problems, e.g., predicting MBIs in special disease populations. 


\subsection{PBPK modelling of enzyme turnover and the gut wall}

PBPK models of the gut wall are conventionally defined as a well-stirred enterocyte/gut wall compartment, or series of compartments describing intestinal transit of drug (Agoram et al., 2001, Zhang et al., 2009, Darwich et al., 2010). Enzyme abundances are, under control conditions $\left(A O_{e n z, i}\right)$, treated as static parameters. Time-varying enzyme activity (Equation 1$)$ is defined as a product of first-order degradation $\left(k_{d e g}\right)$ and zero-order synthesis $\left(A O_{e n z, i} \cdot k_{d e g}\right)$ where $k_{d e g}$ is informed via clinical MBI studies (Yang et al., 2008, Gertz et al., 2008). Following MBI, recovery of CYP3A4 will occur at a $k_{d e g}$ of $0.03 \mathrm{~h}^{-1}$, typically (Certara, 2018, Rowland Yeo et al., 2011, Zhang et al., 2009).

$\frac{d A_{e n z, i}}{d t}=A 0_{e n z, i} \cdot k_{d e g}-A(t)_{e n z, i} \cdot k_{d e g}$

\section{Equation 1}

Physiologically, $k_{d e g}$ can be interpreted as a lumped parameter of enzyme and enterocyte turnover, two nested processes occurring over a similar time scale. In our previous work, we postulated that separation of enterocyte and enzyme turnover may provide a more accurate basis for modelling MBI. Further, this would allow turnover parameters to be determined directly via in vitro/in vivo experiments rather than indirect clinical data (Darwich et al., 2014).

Metabolic enzymes in the gut are produced and degrade within an individual epithelial cell. This occurs as the cell itself is formed at the crypt of the villous and migrates to the tip where it is eliminated via apoptosis/shedding. Through this process the population of enterocytes are maintained at quasi-steady state. The overall enzyme activity is maintained by two nested 
processes at baseline, zero-order formation and elimination of the enterocytes (resulting in a relatively static cell lifespan), and zero-order synthesis and first-order degradation of enzyme (typically described by a conventional 'turnover model'). Considering the reported CYP3A4 gradient along the crypt-villous axis enzyme synthesis should exceed degradation in the individual epithelial cell (Johnson et al., 2001, Kolars et al., 1992). Following MBI, a mixture of cell genesis and enzyme synthesis will govern the recovery of enzyme activity.

In gut disease where villous blunting or atrophy is present, such as untreated coeliac disease and gastrointestinal mucositis (Duncan and Grant, 2003, Shalimar et al., 2013), the villous morphology is perturbed due to changes in enterocyte renewal or apoptosis. It has been reported that this may cause an increase in oral drug exposure of CYP3A4 substrates (Moron et al., 2013, Schultz et al., 2000). An explanation to this is that drug permeation and the fraction absorbed drug that escapes gut wall metabolism $\left(\mathrm{F}_{\mathrm{G}}\right)$ are altered (Johnson et al., 2001, Lang et al., 1996, Smecuol et al., 1997). Theoretically, this can be modelled in at least two ways: either by incorporating enzyme abundance data from healthy and disease as static parameters in a PBPK model. Alternatively, enterocyte turnover data can be used to inform enzyme abundance in healthy and disease. In the latter case assumes separate nesting of enzyme and enterocyte turnover and can potentially result in additional information being gained gained about enterocyte turnover, volume, enzyme abundance and absorption surface area. Further, separation of these turnover processes may become important when gut wall become the target for treatment through interaction with its intracellular components.

Here we report on the development and evaluation of a novel multi-level systems PBPK model, describing the nesting of enzyme and enterocyte turnover. We examine the ability of such a model to predict metabolism in the gut wall following MBI and gut disease, using in 
vitro/in vivo enzyme and enterocyte turnover data. We explore the relevance of considering CYP3A4 maturation and luminal drug-specific accessibility along the crypt-villous axis.

\section{Material and methods}

\subsection{The nested enzyme-within-enterocyte (NEWE) turnover model}

A multi-level systems PBPK model was developed in MATLAB R2017a (Mathworks, Nattick, MA; See Supplementary Material S5 for more details). The gut wall was modelled at four levels: substrate/inhibitor exposure in the intestine, enzyme kinetics, enterocyte kinetics at individual and population level. The pharmacokinetic module described the intestinal luminal amount of substrate/inhibitor over time $\left(A(t)_{\text {lumen }}\right.$; Equation 1). Absorption of drug equalled the first-order rate of absorption $\left(k_{a}\right)$. Disappearance of drug from the gut lumen into the colon (acting as sink) was given by the small intestinal transit time $\left(3.32 \mathrm{~h}, k_{s i t}=0.21 \mathrm{~h}^{-1}\right)$ (Yu et al., 1996).

$\frac{d A_{\text {lumen }}}{d t}=-A(t)_{\text {lumen }} \cdot\left(k_{a}+k_{\text {sit }}\right)$

\section{Equation 1}

Drug concentration in the enterocytes $\left(C(t)_{\text {ent }}\right.$; Equation 2) was a function of absorption from the gut lumen, disappearance of unbound drug ( $f u_{g u t}=1$ assumed) (Yang et al., 2007) through intrinsic unbound metabolic clearance $\left(C L u_{\text {int }}\right)$ scaled by the dynamic CYP3A4 amount $\left(A(t)_{C Y P 3 A 4, G W}\right)$. Total drug concentration in the enterocytes was cleared via villous blood flow into the portal vein $\left(Q_{\text {villi }} \approx 19 \mathrm{~L} / \mathrm{h}\right)$. The volume of enterocytes was set to $0.517 \mathrm{~L}$ in control conditions (based on Simcyp Simulator V16, Certara UK Ltd., Sheffield, UK) (Yang et al., 2007, Olivares-Morales et al., 2016, Certara, 2018, Brown et al., 1997). 


$$
V_{\text {ent }} \cdot \frac{d C_{\text {ent }}}{d t}=A(t)_{\text {lumen }} \cdot k_{a}-C(t)_{e n t} \cdot\left(C L u_{\text {int }} \cdot f u_{g u t} \cdot A(t)_{C Y P 3 A 4, G W}+Q_{v i l l i}\right)
$$

\section{Equation 2}

The gut wall was modelled as a population of enterocytes ( $n=100$ cells) uniformly distributed across relative age/crypt-villous position. The amount of CYP3A4 in the $i^{\text {th }}$ enterocyte was defined as a function of synthesis rate, degradation and MBI (Equation 3). Given that at steady-state (baseline), the level of enzyme is assumed to remain constant over time, the zero order synthesis of enzyme is defined on the basis of degradation at steady-state, $A 0_{C Y P 3 A 4, i}$. $k d e g_{C Y P 3 A 4}$, where $A 0_{C Y P 3 A 4, i}$ represents baseline CYP3A4 amount in the $i^{\text {th }}$ enterocyte (AO ${ }_{C Y P 3 A 4, i}, 66.2 \mathrm{nmol} /$ total gut) (based on Simcyp Simulator V16, Certara UK Ltd., Sheffield, UK) (Certara, 2018) and $k_{d e g_{C Y P 3 A 4}}$ represents the CYP3A4 degradation rate $\left(k_{\text {deg,CYP } 3 A 4}\right)$.

Degradation of enzyme was described as the amount of CYP3A4 in the $i^{\text {th }}$ enterocyte at time $t$ $\left(A(t)_{C Y P 3 A 4, i}\right)$, times $k d e g_{C Y P 3 A 4}$. Inactivation was driven by unbound inhibitor concentration in the enterocytes $\left(I(t)_{\text {ent }} \cdot f u_{g u t}\right)$ and MBI parameters, $k_{\text {inact }}$ (maximum rate of enzyme inhibition) and $K_{I, u}$ (unbound inhibitor concentration producing $50 \%$ of the maximum inhibition rate).

$$
\begin{aligned}
& \frac{d A_{C Y P 3 A 4, i}}{d t}=A 0_{C Y P 3 A 4, i} \cdot k \operatorname{deg}_{C Y P 3 A 4}-A(t)_{C Y P 3 A 4, i} \cdot k d e g_{C Y P 3 A 4} \\
& -A(t)_{C Y P 3 A 4, i} \cdot\left(\frac{k_{\text {inact }} \cdot I(t)_{\text {ent }} \cdot f u_{\text {gut }}}{K_{I, u}+I(t)_{\text {ent }} \cdot f u_{\text {gut }}}\right)
\end{aligned}
$$

\section{Equation 3}

The overall amount of enzyme in the gut wall $\left(A(t)_{C Y P 3 A 4, G W}\right)$ was equal to the total activity of CYP3A4 in the simulated population of enterocytes (Equation 4). In the absence of accessibility considerations (Oliver et al., 1998), $A_{C Y P 3 A 4, i}$ was equal to $A_{C Y P 3 A 4, G W}$, and 
therefore the sum of enzyme activity was equal to the average across the cell population (Equation 5).

$A(t)_{C Y P 3 A 4, G W}=\sum_{i=1}^{n} A(t)_{C Y P 3 A 4, i}$

\section{Equation 4}

$A_{C Y P 3 A 4, G W}=A_{C Y P 3 A 4, i} \rightarrow A(t)_{C Y P 3 A 4, G W}=\frac{\sum_{i=1}^{n} A_{C Y P 3 A 4, i}}{n}$

\section{Equation 5}

The cumulative probability of apoptosis of the $i^{\text {th }}$ enterocyte $\left(e_{i}\right)$ increased at a rate of $k d e g_{\text {ent }}$ over time (the inverse of enterocyte lifespan in hours; Equation 6), this probability could equally be viewed as the relative age or spatial crypt-villous position. The probability of apoptosis at time zero was uniformly distributed between zero and one across the population of simulated enterocytes (Equation 7). Practically this was implemented as evenly spaced probability between 0 and 0.99, for computational reasons (Supplementary Material S5).

$\frac{d e_{i}}{d t}=k d e g_{e n t}$

\section{Equation 6}

$e_{i}(t=0)=\left\{\begin{array}{c}\frac{1}{1-0} \text { for } 0 \leq e<1 \\ 0 \quad \text { for } e<0 \text { or } e \geq 1\end{array}\right.$

\section{Equation 7}

The probability of an apoptosis event, $P(E)$, is given in Equation 8 . Where $e_{j, 0}$ is the initial condition and $k d e g_{\text {ent }} \cdot t$ represents the cumulative age/position along the crypt-villous axis. 


$$
\begin{gathered}
P(E=e): f(t)=e_{j, 0}+\mathrm{kdeg}_{\text {ent }} \cdot t \\
E=e \rightarrow e_{i}(t)=0 \& A(t)_{C Y P 3 A 4, i}=A 0_{C Y P 3 A 4, i}
\end{gathered}
$$

\section{Equation 8}

\subsubsection{CYP3A4 crypt-villous axis gradient}

Data suggests that the amount of CYP3A4 increases along the crypt-villous axis to reach the highest levels at the tips of the villi. This was considered using by extending the NEWE model. The implemented CYP3A4 crypt-villous gradient was based on immunoreactive staining data of protein in one individual (Kolars et al., 1992). The limitations of the dataset meant that it would serve as an illustrative example only. The published image, Figure 2 in (Kolars et al., 1992), was extracted and analysed in MATLAB using regions of interest (ROI) image processing. Parameter estimation was carried out using lsqnonlin (MATLAB) (Supplementary S1).

A CYP3A4 maturation function (Equation 9) was implemented where abundance at baseline $\left(A 0_{C Y P 3 A 4, i:} 0.46, \mathrm{CV}\right.$ [coefficient of variation]: $\left.5.31 \%\right)$ and a scalar for synthesis $(\beta: 1.26$, $\mathrm{CV}: 4.12 \%)$ were estimated. The function, based on relative expression, was then scaled to the overall enzyme abundance in the gut (Supplementary Material S1). For the $i^{\text {th }}$ enterocyte, at the time of cell mitosis CYP3A4 content $\left(A(O)_{C Y P 3 A 4, i}\right)$ was equal to $\mathrm{A} 0_{\mathrm{CYP} 3 \mathrm{~A} 4, \mathrm{i}}$.

$$
\begin{aligned}
& \frac{d A_{C Y P 3 A 4, i}}{d t}=A 0_{C Y P 3 A 4, i} \cdot \beta \cdot k d e g_{C Y P 3 A 4}-A(t)_{C Y P 3 A 4, i} \cdot k d e g_{C Y P 3 A 4} \\
& A(0)_{C Y P 3 A 4, i}=A 0_{C Y P 3 A 4, i}
\end{aligned}
$$

\section{Equation 9}




\subsubsection{Accessbility}

It has been postulated that highly permeable drugs display significant concentration variations along crypt-villous axis as absorption exceeds diffusion in the gut lumen, limiting accessibility to the epithelial absorption surface area (Oliver et al., 1998). To investigate the impact of this a drug-specific accessibility gradient along the crypt-villous axis was implemented into the NEWE model.

The luminal depot compartments were divided into a number of sections equal to the number of simulated enterocytes. The gradient was calculated as per Oliver et al. (1998), using villous dimensions, drug permeability and diffusion as input parameters. Drug-specific effective jejunal permeability $\left(P_{\text {eff }}[\mathrm{cm} / \mathrm{s}]\right)$ was derived from $k_{a}\left[\mathrm{~s}^{-1}\right]$, based on $\mathrm{Yu}$ and Amidon (1999), where $r_{s i}(1.75 \mathrm{~cm})$ is the small intestinal radius (Equation 10). Epithelial permeability $\left(P_{e p}\right)$ was calculated based on the unbound fraction in the unstirred water layer $\left(f u_{U W L}=1\right.$, assumed), and plicae circulares and villous expansion factors, $p e=3$ and $v e=10$, respectively (Equation 11) (Sugano, 2009).

$P_{e f f}=\frac{k_{a} \cdot r_{s i}}{2}$

\section{Equation 10}

$P_{e p}=\frac{P_{e f f}}{f u_{U W L} \cdot p e \cdot v e}$

\section{Equation 11}


The molecular radius $\left(r_{w}\right)$ was given by molecular weight $(m w)$, density $(\rho)$ and Avogrado's number $\left(N_{A}\right)$ (Equation 12), $r_{w}$ was then used to calculate the diffusion coefficient $(D$; Equation 13) - $\mathrm{k}_{\mathrm{B}}$ : Boltzmann's constant, $T$ : absolute temperature $[\mathrm{K}], \mu$ : viscosity of water.

$r_{w}=\left(m w \cdot \frac{3}{\rho \cdot N_{A} \cdot 4 \cdot \pi}\right)^{1 / 3}$

\section{Equation 12}

$D=k_{B} \cdot \frac{T}{6 \cdot \pi \cdot \mu \cdot r_{w}}$

\section{Equation 13}

The approximate solution for the drug gradient along the crypt-villous axis is given in Equation 14 and is dependent on the diffusion length along the inter-villous space $(y)$. The equation uses the dimensionless scalar $\epsilon$, based on $P_{e p}$, inter-villous channel radius $(b)$ and $D$ (Equation 15), and $\gamma$, based on $P_{e p}, D, b$ and channel depth ( $h$; Equation 16).

$C \sim \frac{\cosh (\gamma-y)}{\cosh \gamma}-\epsilon \cdot \frac{\sinh y}{\sinh \gamma \cdot \cosh \gamma}+O\left(\epsilon^{2}\right)$

\section{Equation 14}

$\epsilon=\sqrt{\frac{P_{e p} \cdot b}{D}}$

\section{Equation 15}

$\gamma=\sqrt{\frac{P_{e p} \cdot h^{2}}{D \cdot b}}$

\section{Equation 16}




\subsubsection{Enterocyte volume module}

To allow the prediction of enterocyte volume changes in gut disease based on perturbed mitosis/apoptosis rates, an enterocyte volume module was developed as an extension to the NEWE model. The enterocyte volume module was implemented as a discrete event simulation, where mitosis $(M)$ was modelled as a cumulative probability (Equation 17), based on $k_{d e g_{\text {ent }}}$ and number of enterocytes at baseline $\left(n_{\text {ent }-0}\right)$. Apoptosis $(A)$ of a given cell $\left(\mathrm{a}_{\mathrm{j}}\right)$ was driven by the cumulative probability (Equation 18). Baseline likelihood of $A\left(a_{j, 0}\right)$ was defined as per Equation 7.

$$
\begin{gathered}
P(M<m): f(t)=m_{j, 0}+\frac{1}{\mathrm{kdeg}_{\text {ent }} \cdot n_{\text {ent-0 }}} \cdot t \\
M=m \rightarrow n_{\text {ent }}(t)=n_{\text {ent }}(t)+1
\end{gathered}
$$

\section{Equation 17}

$$
\begin{gathered}
P\left(A<a_{j}\right): \quad f(t)=a_{j, 0}+\mathrm{kdeg}_{\text {ent }} \cdot t \\
A<a \rightarrow n_{\text {ent }}(t) \& n_{\text {ent }}>0=n_{\text {ent }}(t)-1
\end{gathered}
$$

\section{Equation 18}

Approximate MATLAB run times were as follows for single dose simulations, NEWE: 3 seconds (s), NEWE - accessibility and CYP3A4 gradient: 25 s, on a 64-bit Intel Core i7 3.40 GHz, 16 GB RAM, Microsoft Windows 10, PC.

\subsection{Grapefruit juice-NEWE model and Bayesian optimization}

Optimal turnover parameters were explored using estimated CYP3A4 activity over time based on area under the plasma concentration-time curve (AUC) data, following complete inhibition by grapefruit juice (GFJ) for substrates nisoldipine, felodipine and midazolam 
(extensively metabolised via CYP3A4, not actively transported in the gut) (Lundahl et al., 1995, Takanaga et al., 2000, Greenblatt et al., 2003). Analysis was carried out using the Bayesian optimization algorithm in MATLAB and a weighted least squares objective function (bayesopt, MATLAB) constraining parameter ranges to the mean $\pm 2 \cdot \mathrm{SD}$ (standard deviation; Supplementary Material S2). Simulated CYP3A4 recovery was compared with the lumped first-order turnover approach $\left(k_{d e g}=0.03 \mathrm{~h}^{-1}\right)$ based on a priori turnover data and following Bayesian optimization. Performance was evaluated by visual comparison to observed data and by calculating the mean absolute error (MAE; Equation 18):

$M A E=\frac{\sum_{i=1}^{n}\left|y_{i}-x_{i}\right|}{n}$

\section{Equation 19}

\subsection{Simulation study 1: Mechanism-based inhibition}

Simulations, matching observed clinical dosing protocols, were carried out for nine DDIs involving mechanism-based/mixed CYP3A4 inhibitors/inducers (azithromycin, clarithromycin, diltiazem, erythromycin, fluoxetine, mibefradil, nefazodone, roxithromycin and saquinavir) and midazolam (probe substrate; See input parameter table, Table S3.1 in Supplementary Material S3). $\mathrm{F}_{\mathrm{G}}$ was calculated based on the dynamic simulations and compared to the conventional well-stirred enterocyte model. DDIs were scaled using a static model of hepatic clearance and compared to observed AUC ratios (Supplementary Material S3). Evaluation was carried by visual inspection, and calculating the mean absolute difference (MD; See Equation 18).

A theoretical simulation study was carried out (multiple dosing of inhibitor $500 \mathrm{mg} \cdot 7, \tau=24 \mathrm{~h}$, substrate $8 \mathrm{mg}$, lag time $2 \mathrm{~h}$ ) to examine the impact of the NEWE region over the region of 
observed $k_{\text {inact }}, K_{I, u}$, substrate metabolism $\left(\mathrm{F}_{\mathrm{G}}\right)$ and absorption $\left(\mathrm{k}_{\mathrm{a}}\right.$ for substrate and inhibitor). The examined space of $k_{\text {inact }}\left(1.49-36.6 \mathrm{~h}^{-1}\right)$ and $K_{I, u}(0.1-109.9 \mu \mathrm{M})$ values were based on Zhou et al. (2005) (Supplementary Material S3). Gut wall metabolism was investigated at $F_{G}$ of $0.25,0.50$ and 0.75 and $\mathrm{k}_{\mathrm{a}}$ of $0.25,1.5,3.5 \mathrm{~h}^{-1}$ (total of 1,125 simulations).

\subsection{Simulation study 2: Disease modelling}

Modelling of gut disease was carried out by simulating disease specific enterocyte volumes and CYP3A4 abundances based on observed changes in enterocyte turnover. For untreated coeliac disease, the enterocyte lifespan was altered to 0.25 days (Brigic et al., 2012). In the case of gastrointestinal mucositosis, the mitosis rate was scaled to one seventh of the default production rate (Keefe et al., 2000). Further, in untreated coeliac disease, $Q_{\text {villi }}$ was set to $150 \%$ of that in healthy controls (Alvarez et al., 1993).

Disease impact on absorption surface area was considered by assuming a linear scalar on $\mathrm{P}_{\mathrm{eff}}$ normalised pe, where $P_{\text {eff, disease }}=P_{\text {eff }}\left(1+9 \cdot V_{\text {ent,disease }} / V_{\text {ent }}\right)$. For simvastatin and cyclosporine, $C L u_{\text {int }}$ was informed by reported $\mathrm{F}_{\mathrm{G}}$ values (0.08 and 0.44, respectively) (Yang et al., 2007, Gertz et al., 2010). For isovuconazole, $C L u_{\text {int }}$ was back-calculated from intravenous clearance assuming CYP3A4 metabolism only (Townsend et al., 2018). $\mathrm{F}_{\mathrm{G}}$ values in gut disease were

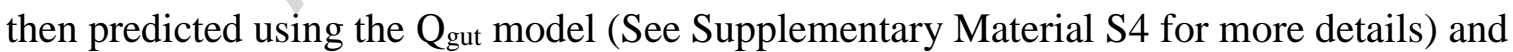
compared to observed pharmacokinetic parameters, AUC and $\mathrm{C}_{\max }$ (maximum concentration). 


\section{Results}

\subsection{The nested enzyme-within-enterocyte (NEWE) model}

The nested enzyme-within-enterocyte (NEWE) model is presented in Figure 1. The model included a pharmacokinetic module (Figure 1B), describing the substrate/inhibitor exposure in the gut lumen, enterocytes, and overall CYP3A4 activity in the gut over time. Three extensions of the NEWE model were developed and also evaluated (Figure 1A): CYP3A4 maturation gradient along the crypt-villous axis (indicated in Figure 1A), a drug-specific accessibility gradient along the crypt-villous axis on the apical side (Figure 1A), and a combined CYP3A4 maturation and accessibility model. An enterocyte volume simulation module was also developed as an extension (Supplementary Material S5).

Figure 2 shows a representative simulation output from the NEWE model. The baseline probability of apoptosis across the population of simulated enterocytes $(P(E)$, Equation $8 ; n$ cells=100) was assigned a uniform distribution between 0 and 1 (Figure 2A). Accumulation of $P(E)$ occurred at a rate of $k d e g_{\text {ent }}$, where $P(E)=1$ triggered cell replacement through a discrete event (Figure 2B, left y axis, blue). The right y axis (orange) in Figure 2B indicates the CYP3A4 maturation as the enterocyte migrates along the crypt-villous axis. The enterocyte population simulation module allowed discrete event simulation of quasi-steady state population of enterocytes (Figure 2C). Figure 2D indicates enterocyte concentration of the inhibitor (clarithromycin) following multiple dosing and the substrate drug (midazolam) following enzyme inhibition. Figure $2 \mathrm{E}$ shows the corresponding reduction in intestinal CYP3A4 activity following multiple dose inhibition. Figure 2F illustrates the crypt-villous gradient of substrate and inhibitor in the gut lumen following single dosing, as per the accessibility module. 


\section{A}

NEWE model: conceptual diagram

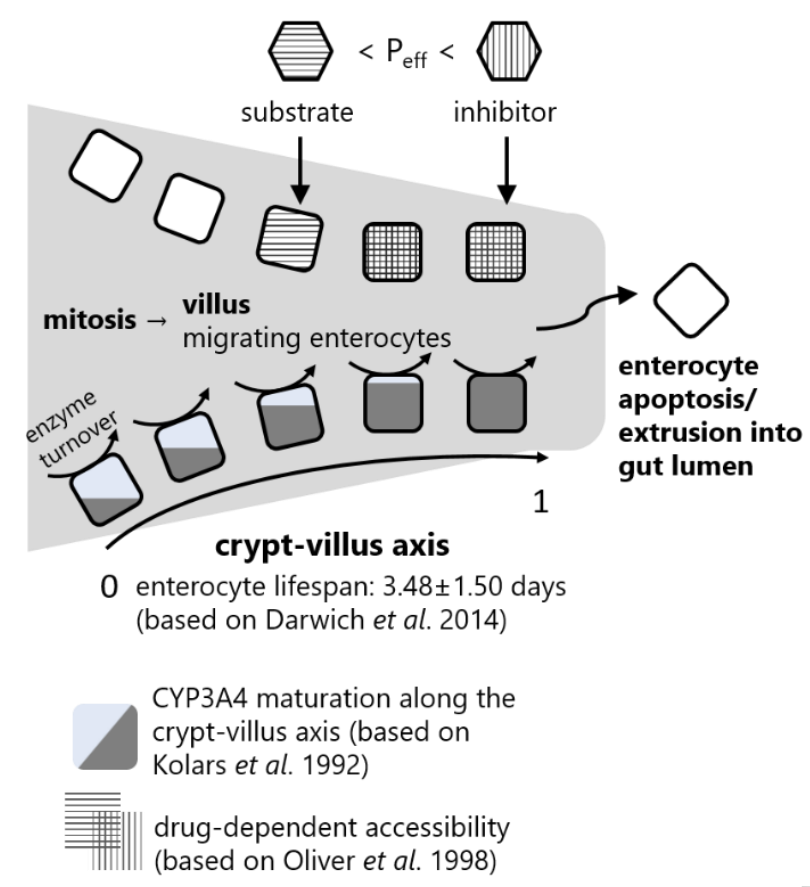

B

NEWE model: pharmacokinetic model

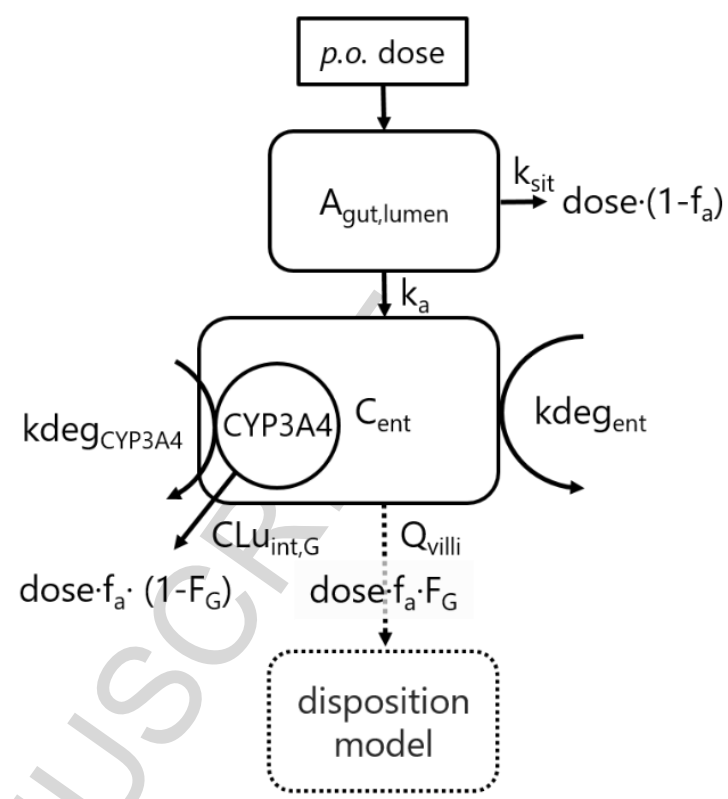

Figure 1. Diagram of the nested enzyme-within-enterocyte (NEWE) model. A: conceptual diagram indicating the drug-specific effective permeability $\left(\mathrm{P}_{\text {eff }}\right)$ dependent accessibility gradient and crypt-villous CYP3A4 gradient. B: pharmacokinetic model diagram showing drug disposition following oral dosing into the gut lumen depot $\left(A_{\text {gut }}\right.$ lumen $)$, first-order transfer through small intestinal transit $\left(k_{s i t}\right)$ and absorption into the enterocytes $\left(k_{a}\right)$. Enterocytic drug concentration $\left(C_{e n t}\right)$ can then be cleared through CYP3A4 dependent metabolism $\left(C L u_{i n t, G}\right)$ or transferred to a pharmacokinetic disposition model as a function of the villous blood flow $\left(Q_{\text {villi }}\right)$. Turnover of intestinal CYP3A4 is driven by the first-order rate constant kdegCYP3A, nested within the enterocytes that turnover at a rate equal to $\left.k d e g_{E n t}\right)$. DES: discrete event simulation, $\mathrm{f}_{\mathrm{a}}$ : fraction of oral dose absorbed, $\mathrm{F}_{\mathrm{G}}$ : fraction of absorbed drug escaping gut wall metabolism, p.o.: per oral. 

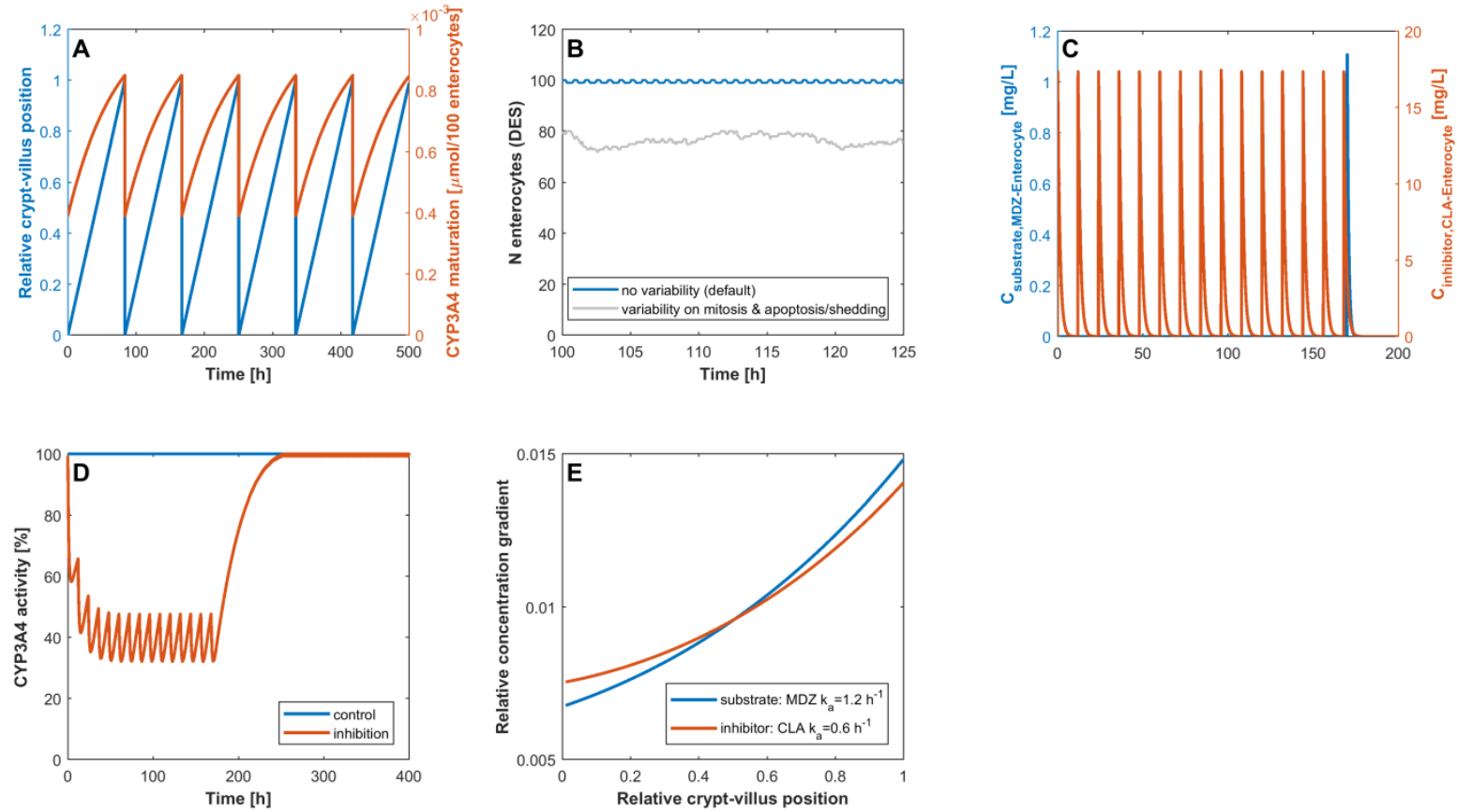

Figure 2. Simulation output based on the full nested enzyme-within-enterocyte (NEWE) model (including CYP3A4 gradient, accessibility). A: left y-axis: relative crypt-villous position of an individual enterocyte over time, right y-axis: CYP3A4 abundance over time based on maturation along the crypt-villous axis. B: Population number of enterocytes over time based on discrete event simulations. C: left y-axis: substrate drug (MDZ: midazolam) enterocyte concentration over time, right y-axis: inhibitor drug (CLA: clarithromycin) concentration over time following multiple dosing. D: CYP3A4 activity in the gut wall at control and following inhibition through multiple dosing of CLA. E: relative gradient of MDZ and CLA in the intestinal lumen following oral administration (based on accessibility).

3.2. Grapefruit juice as a probe for nested intestinal CYP3A4 and enterocyte turnover 
Recovery of enzyme activity was simulated following MBI by GFJ and compared to three clinical datasets of CYP3A4 probe drugs not subject to active transport (felodipine, nisoldipine and midazolam) (Greenblatt et al., 2003, Takanaga et al., 2000, Lundahl et al., 1995). The turnover parameters used for the NEWE simulations, $k_{d e g_{\text {ent }}}\left(0.012 \mathrm{~h}^{-1}\right)$ and $\operatorname{kdeg}_{\text {CYP3A4 }}\left(0.014 \mathrm{~h}^{-1}\right)$, were informed via combined experimental data (Darwich et al., 2014, Yang et al., 2008). Simulations using the default NEWE model (Figure 3A, MAE: 0.192) and NEWE model with CYP3A4 gradient (Figure 3B, MAE: 0.191) closely matched the simulated CYP3A4 recovery profile of the conventional well-stirred enterocyte model at a $k_{d e g}=0.03 \mathrm{~h}^{-1}$ (MAE: 0.179). This suggested the use of measured systems data to inform the turnover parameters of the NEWE model gave a reasonable estimate of in vivo enzyme turnover in the gut wall.

Turnover parameters of the NEWE model were estimated based on the clinical GFJ data using a Bayesian optimization algorithm in order to investigate the objective function surface corresponding to mean $\pm 2 \cdot \mathrm{SD}$ for $k d e g_{\text {ent }}$ and $k \operatorname{keg}_{\text {CYP3A4 }}$. The analysis indicated that for the default NEWE model the optimal parameter combination was located close to the lower percentile of $k d e g_{\text {ent }}\left(0.005 \mathrm{~h}^{-1}\right)$ and upper percentile of $k d e g_{C Y P 3 A 4}\left(0.035 \mathrm{~h}^{-1}\right.$; MAE: 0.162 , Figure 3A). Analysis of the NEWE model with CYP3A4 gradient located the global minimum of $k$ deg $_{\text {ent }}$ to $0.024 \mathrm{~h}^{-1}$ (MAE: 0.178, Figure 3B). One interpretation of this is that the default NEWE model may be misspecified and the CYP3A4 gradient gave a more accurate description of enzyme recovery following MBI (See Supplementary Material S2). Interestingly, the conventional model approach required a lumped first-order $\mathrm{k}_{\mathrm{deg}}$ in the region of $0.06-0.07 \mathrm{~h}^{-1}$ in order to describe a similar recovery profile to that indicated by fittings using the default NEWE model and NEWE model with CYP3A4 gradient (Figure 
3C). This implied the recovery to be approximately two times faster when accounting for the subset of clinical GFJ data included herein.
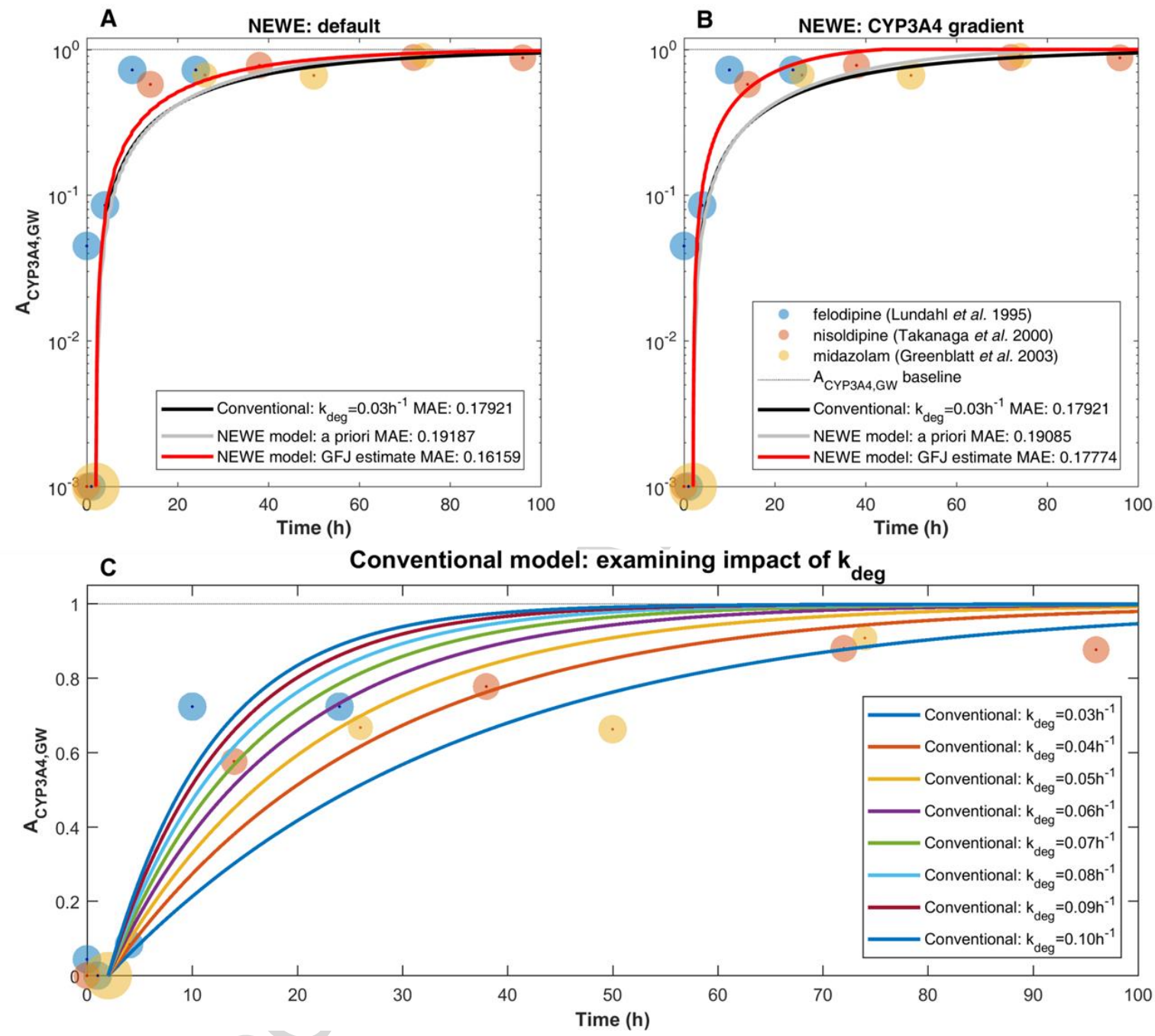

Figure 3. Simulated and observed enzyme recovery over time following complete inhibition of intestinal activity of CYP3A4 (ACYP3A4,GW) by oral grapefruit juice (GFJ), A: default NEWE model as compared to conventional model, B: NEWE model with CYP3A4 gradient as compared to conventional model. C: Simulations examining the impact of varying $\mathrm{k}_{\mathrm{deg}}$, using the conventional model, on the recovery of the analysed clinical data points. Bubble plot sizes indicate relative number patients per observed data point. $k_{\text {deg }}$ : lumped first-order 
rate of enzyme degradation, MAE: mean absolute error, NEWE: nested enzyme-within enterocyte model (Lundahl et al., 1995, Takanaga et al., 2000, Greenblatt et al., 2003).

\subsection{Nested turnover and mechanism-based inhibition of gut wall metabolism}

Nine clinical MBI trials, with midazolam as the CYP3A4 probe substrate drug, were simulated using the four variations of the NEWE model and the conventional well-stirred enterocyte model. NEWE predictions of $F_{G}$ ratio with and without inhibitor $\left(\mathrm{F}_{\mathrm{G}}{ }^{\prime} / \mathrm{F}_{\mathrm{G}}\right)$ were compared to that of the conventional model (Figure 4A). The default NEWE and NEWE with CYP3A4 gradient displayed comparable DDI predictions to the conventional model (MD: 0.006 and MD: 0.002, respectively). The NEWE model considering accessibility, with and without CYP3A4 gradient, displayed an apparently lower impact of $\mathrm{MBI}$ on $\mathrm{F}_{\mathrm{G}}{ }^{\prime} / \mathrm{F}_{\mathrm{G}}(\mathrm{MD}$ : 0.07 and MD: 0.075, respectively).

The $\mathrm{F}_{\mathrm{G}}{ }^{\prime} / \mathrm{F}_{\mathrm{G}}$ predictions were combined with a static model to predict the hepatic DDI effect to allow comparison to clinically observed AUC ratios (AUC'/AUC; Figure 4B). All models appeared to perform similarly when combined with the predicted systemic effect. The NEWE model with accessibility displayed the smallest MAE of 3.584 as compared to a MAE of 3.812 for the conventional model. The NEWE model with accessibility and CYP3A4 showed similar performance with a MAE of 3.63 (See Supplementary Material, Table S3.3 for more details). 

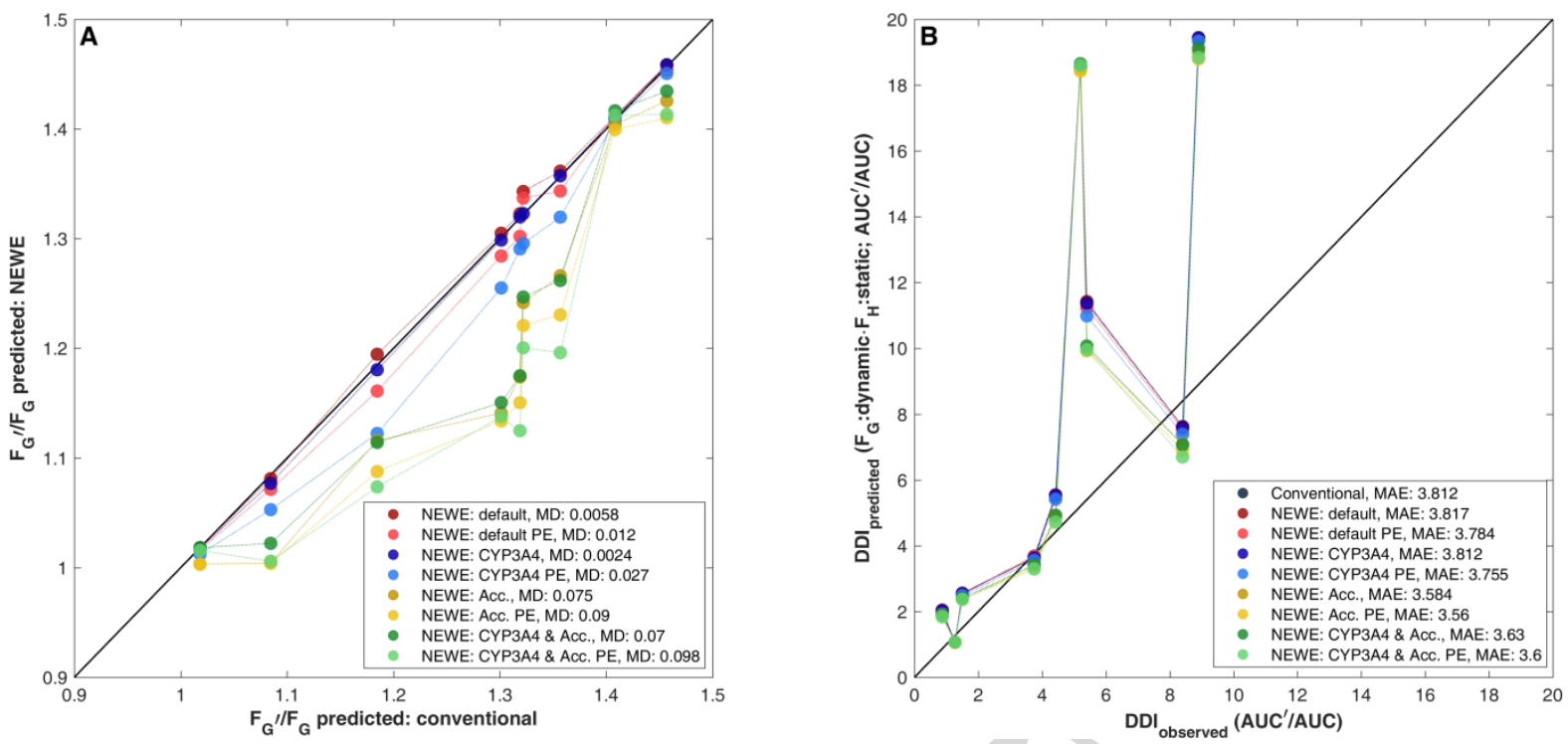

Figure 4. A: predicted $F_{G}$ ratio $\left(F_{G}, F_{G}\right)$ following mechanism-based inhibition using the NEWE model as compared to the conventional enterocyte model. B: Predicted AUC ratio (AUC'/AUC) following mechanism-based inhibition as compared to observed data. Acc: accessibility, AUC: area under the concentration-time curve; $\mathrm{F}_{\mathrm{G}}$ : fraction of absorbed drug that escapes gut wall metabolism, MD: mean absolute difference, MAE: mean absolute error, NEWE: nested enzyme-within-enterocyte model, PE: parameter estimation (optimised model). Details and references to observed data are given in Supplementary Material S3.

\subsection{Exploratory simulation study: a midazolam-clarithromycin case study}

An exploratory simulation study was carried out using the four NEWE models and the conventional enterocyte model to identify the parameter space that showed the greatest difference in $\mathrm{MBI}$ predictions. This was carried out by comparing ratio of predicted $\mathrm{F}_{\mathrm{G}}{ }^{\prime} / \mathrm{F}_{\mathrm{G}}$ of the NEWE models to the $\mathrm{F}_{\mathrm{G}}{ }^{\prime} / \mathrm{F}_{\mathrm{G}}$ of the conventional model over a realistic range of $k_{\text {inact }}$ and $k_{I, u}$ following multiple dosing of an inhibitor, varying the $k_{a}$ of the inhibitor and substrate and $F_{G}$ of the substrate drug. Little difference was observed for the default NEWE model (maximum difference of approximately $3 \%$ at low $\mathrm{F}_{\mathrm{G}}$, high inhibitor potency), and the 
NEWE model with CYP3A4 gradient (maximum difference of approximately 2\%;

Supplementary Material S3). However for the NEWE model with accessibility and NEWE model with accessibility and CYP3A4 gradient an approximately 50\% difference was seen for the upper range of $k_{\text {inact }}$ values and lower range of $K_{I, u}$ values when the substrate was subject to high intestinal metabolism $\left(\mathrm{F}_{\mathrm{G}}=0.25\right)$ and displayed similar or lower absorption rate compare to the inhibitor (Figure 5A and 5B). Similar trends were observed at a substrate $\mathrm{F}_{\mathrm{G}}$ of 0.50 and 0.75 , although these effects were far less pronounced at around $30 \%$ and $15 \%$ difference, respectively (Figure 5D-I).
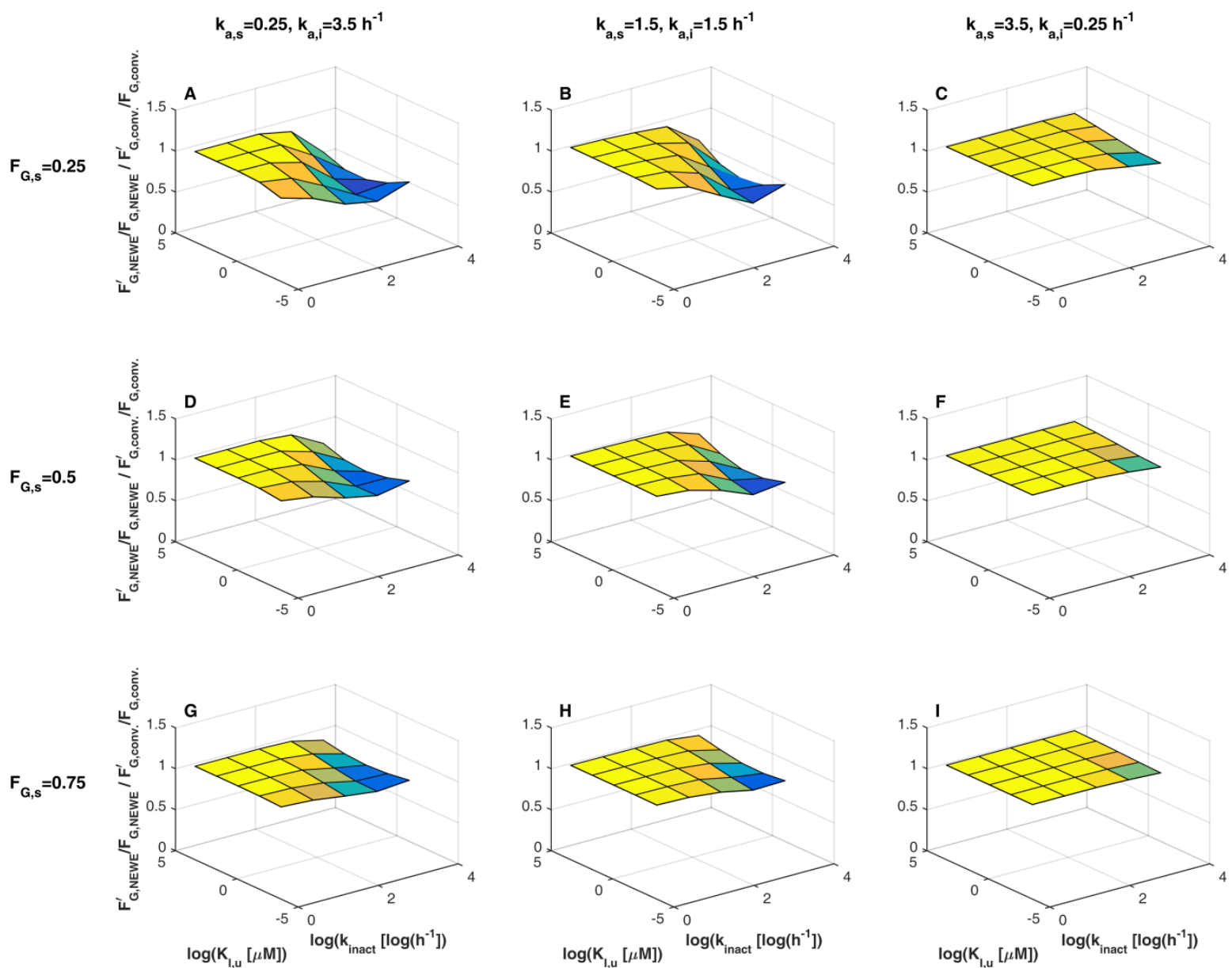
Figure 5. Simulated $\mathrm{F}_{\mathrm{G}}$ ratio $\left(\mathrm{F}_{\mathrm{G}, \mathrm{NEWE}} / \mathrm{F}_{\mathrm{G}, \mathrm{NEWE}}\right)$ of the $\mathrm{NEWE}$ model relative to the conventional model (F' ${ }_{\mathrm{G}, \mathrm{conv}} / \mathrm{F}_{\mathrm{G}, \mathrm{conv}}$ ) following multiple dosing of mechanism-based inhibitor varying the maximum inhibition rate constant $\left(\mathrm{k}_{\text {inact }}\right)$ and the unbound concentration producing $50 \%$ of maximum inhibition rate $\left(\mathrm{K}_{\mathrm{I}, \mathrm{u}}\right) . \mathbf{A}: \mathrm{F}_{\mathrm{G}, \mathrm{s}}=0.25, \mathrm{k}_{\mathrm{a}, \mathrm{s}}=0.25 \mathrm{~h}^{-1}$ and $\mathrm{k}_{\mathrm{a}, \mathrm{i}}=3.5 \mathrm{~h}^{-1}$, B: $\mathrm{F}_{\mathrm{G}, \mathrm{s}}=0.25, \mathrm{k}_{\mathrm{a}, \mathrm{s}}=1.5 \mathrm{~h}^{-1}$ and $\mathrm{k}_{\mathrm{a}, \mathrm{i}}=1.5 \mathrm{~h}^{-1}, \mathbf{C}: \mathrm{F}_{\mathrm{G}, \mathrm{s}}=0.25, \mathrm{k}_{\mathrm{a}, \mathrm{s}}=3.5 \mathrm{~h}^{-1}$ and $\mathrm{k}_{\mathrm{a}, \mathrm{i}}=0.25 \mathrm{~h}^{-1}$, D: $\mathrm{F}_{\mathrm{G}, \mathrm{s}}=0.5, \mathrm{k}_{\mathrm{a}, \mathrm{s}}=0.25 \mathrm{~h}^{-1}$ and $\mathrm{k}_{\mathrm{a}, \mathrm{i}}=3.5 \mathrm{~h}^{-1}, \mathbf{E}: \mathrm{F}_{\mathrm{G}, \mathrm{s}}=0.5, \mathrm{k}_{\mathrm{a}, \mathrm{s}}=1.5 \mathrm{~h}^{-1}$ and $\mathrm{k}_{\mathrm{a}, \mathrm{i}}=1.5 \mathrm{~h}^{-1}, \mathbf{F}: \mathrm{F}_{\mathrm{G}, \mathrm{s}}=0.5$, $\mathrm{k}_{\mathrm{a}, \mathrm{s}}=3.5 \mathrm{~h}^{-1}$ and $\mathrm{k}_{\mathrm{a}, \mathrm{i}}=0.25 \mathrm{~h}^{-1}, \mathbf{G}: \mathrm{F}_{\mathrm{G}, \mathrm{s}}=0.75, \mathrm{k}_{\mathrm{a}, \mathrm{s}}=0.25 \mathrm{~h}^{-1}$ and $\mathrm{k}_{\mathrm{a}, \mathrm{i}}=3.5 \mathrm{~h}^{-1}, \mathbf{H}: \mathrm{F}_{\mathrm{G}, \mathrm{s}}=0.75, \mathrm{k}_{\mathrm{a}, \mathrm{s}}=1.5$ $\mathrm{h}^{-1}$ and $\mathrm{k}_{\mathrm{a}, \mathrm{i}}=1.5 \mathrm{~h}^{-1}, \mathbf{I}: \mathrm{F}_{\mathrm{G}, \mathrm{s}}=0.75, \mathrm{k}_{\mathrm{a}, \mathrm{s}}=3.5 \mathrm{~h}^{-1}$ and $\mathrm{k}_{\mathrm{a}, \mathrm{i}}=0.25 \mathrm{~h}^{-1} . \mathrm{F}_{\mathrm{G}}$ : fraction of absorbed drug escaping gut wall metabolism, $\mathrm{i}=$ inhibitor, $\mathrm{k}_{\mathrm{a}}$ : first-order absorption rate constant, $\mathrm{s}$ : substrate.

\subsection{Predicting gut wall metabolism in special disease populations}

Several studies have reported on the oral drug exposure in gut disease, including gastrointestinal mucositis and untreated coeliac disease (Moron et al., 2013, Kovanda et al., 2017, Schultz et al., 2000). Both of these conditions are characterised by altered villous morphology, this likely due to changes in enterocyte turnover, lifespan or mitosis (Duncan and Grant, 2003, Shalimar et al., 2013). One of the aims of the NEWE model was therefore to test the hypothesis whether altered oral drug exposure in gut disease could be explained by perturbations in enterocyte turnover leading to a loss in CYP3A4 activity and permeability surface area. Here we examine three cases of gut disease-drug interactions: cyclosporine in mucositis as a positive control, isavuconazole in mucositis as a negative control, and simvastatin in untreated coeliac disease. Predictions of enterocyte volume and CYP3A4 abundance were carried out using the NEWE model and $\mathrm{F}_{\mathrm{G}}$ predictions were carried out using the $\mathrm{Q}_{\text {gut }}$ model informed by the anticipated changes in enzyme abundance, absorption area and villous blood flow (Supplementary Material S4). 


\subsubsection{Oncology and mucositis: cyclosporine A and isavuconazole}

Gastrointestinal mucositis is a common side effect following chemo- and radiotherapy in oncology patients (Duncan and Grant, 2003). Mucositis results in villous blunting and atrophy in the intestine. It has been reported that this is the result of a seven-fold higher apoptosis rate of newly formed enterocytes in the crypts of the villi in chemotherapy for cancer (Keefe et al., 2000).

Cyclosporine A, immunosuppressant, is widely used clinically to prevent graft rejection. The drug is a biopharmaceutics classification system (BCS) class IV compound (poorly soluble and permeable), mainly metabolised via CYP3A4. Cyclosporine A displays an $\mathrm{F}_{\mathrm{G}}$ of around 0.44 (Gertz et al., 2010, Freeman, 1991, Ghadi and Dand, 2017). Schultz, and co-workers (Schultz et al., 2000), studied the effect of mucositis on oral cyclosporine A exposure, where the drug displayed an approximately 1.6-fold higher exposure compared to controls with an observed mean $\mathrm{C}_{\max }$ ratio of 1.59 and $\mathrm{AUC}$ ratio of 1.57 (Figure $6 \mathrm{~A}$ and $6 \mathrm{~B}$ ).

Simulations were carried out using the enterocyte volume module assuming the rate of mitosis to be seven times lower compared to default (based on seven-fold increase in apoptosis in the crypts) (Keefe et al., 2000). This led to a proportional decrease in the total enterocyte volume once the steady state level was reached (Figure 6C). An $\mathrm{F}_{\mathrm{G}}$ ratio of 1.34 in mucositis compared to controls was predicted using the NEWE model. The qualitative trend was comparable to the observed change in oral AUC, although not able to fully explain the quantitative trend in the observed data (Figure 6D). 

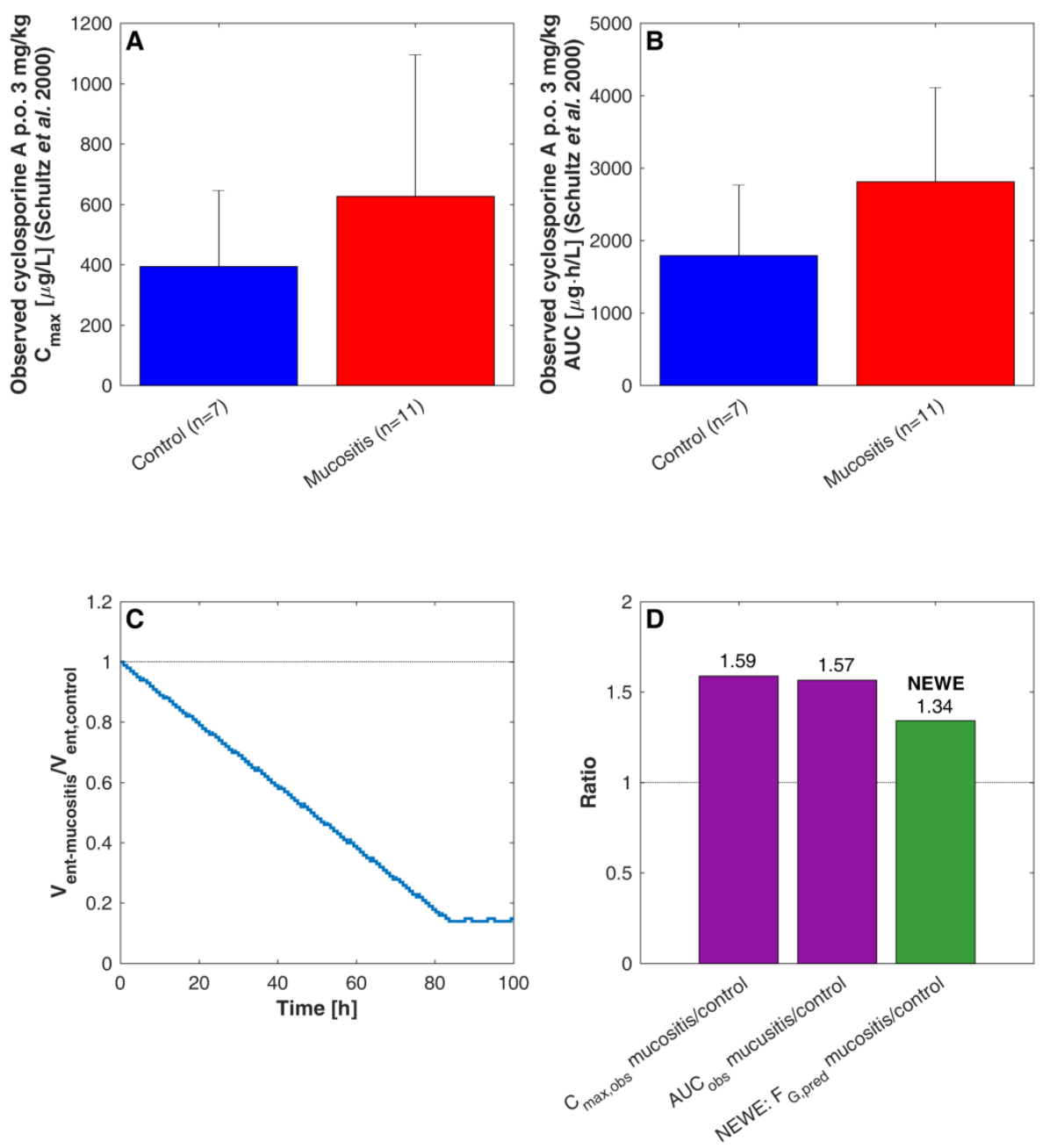

Figure 6. Observed impact of gastrointestinal mucositis on oral cyclosporine A $C_{\max }$ (maximum concentration) and AUC (area under the concentration-time curve) and simulated impact on $\mathrm{F}_{\mathrm{G}}$ (fraction of absorbed drug escaping gut wall metabolism) using the default NEWE model as compared to controls. A: Observed Cmax in mucositis and controls, B: Observed AUC in mucositis and controls, C: Simulated relative enterocyte volume in mucositis as compared to controls $\left(\mathrm{V}_{\text {ent,mucositis }} / \mathrm{V}_{\text {ent,control }}\right)$ where enterocyte turnover is perturbed to the disease state at time $=0 \mathrm{~h}$ and the new steady state volume is reached at around 80h following disease induced turnover change, D: Observed ratios of pharmacokinetic parameters and simulated $F_{G}$ ratio in mucositis compared to controls (Schultz et al., 2000). 
Predictions of the impact of mucositis were carried out for isavuconazole, broad spectrum antifungal agent, BCS class I (highly soluble and permeable). The drug displays a low intravenous clearance and is mainly metabolised by CYP3A4, predicting an $\mathrm{F}_{\mathrm{G}}$ of approximately 0.93 (Townsend et al., 2018, Falci and Pasqualotto, 2013, Schmitt-Hoffmann et al., 2006). Kovanda, and co-workers (Kovanda et al., 2017), reported a statistically insignificant reduction in oral AUC (ratio of 0.92) and oral bioavailability (ratio of 0.88 ) (Figure 7A and 7B). Predictions of $F_{G}$ in mucositis using the NEWE model were in agreement with the indirect observed data, where the observed effect on $\mathrm{F}_{\text {oral }}$ (oral bioavailability) and AUC, and simulated $\mathrm{F}_{\mathrm{G}}$ were negligible (Figure 7C).
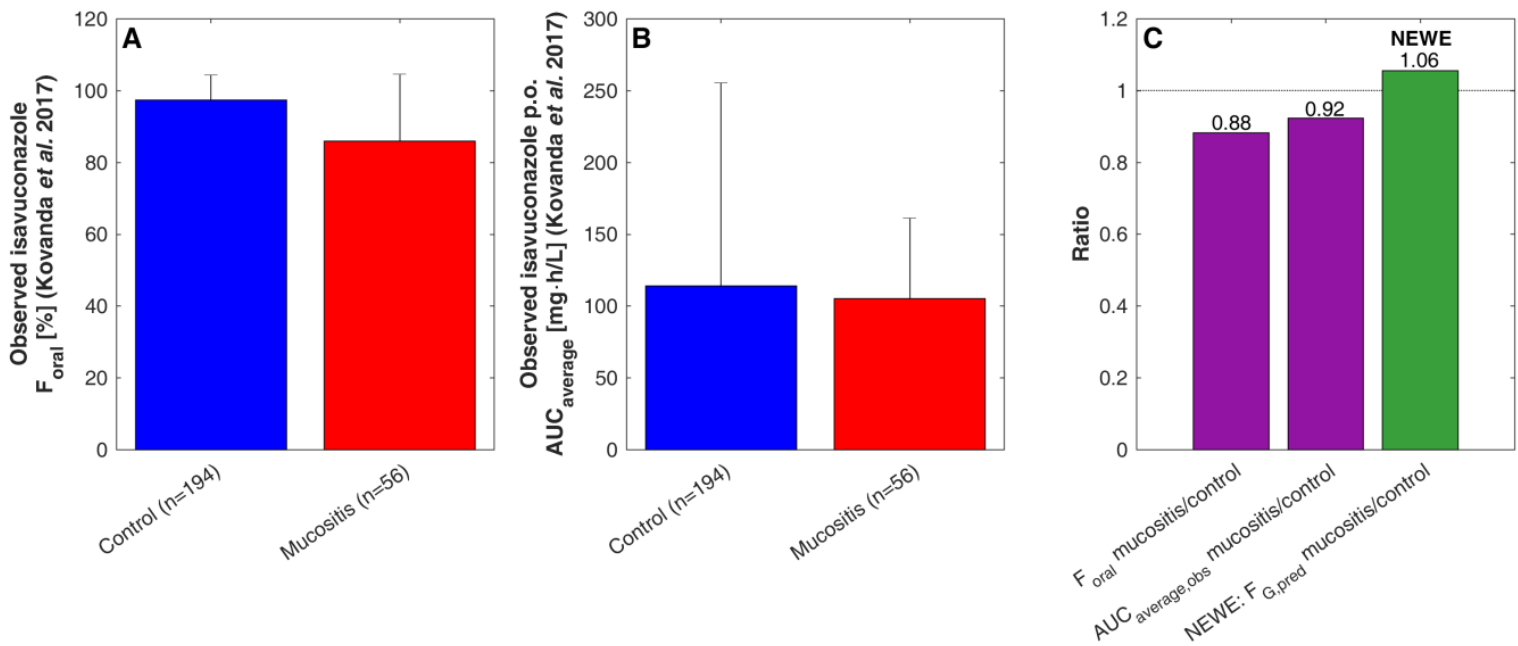

Figure 7. Observed and simulated impact of gastrointestinal mucositis on oral exposure of isavuconazole. A: Mean observed oral bioavailability $\left(\mathrm{F}_{\text {oral }}\right)$ in mucositis and controls (error bars indicate standard deviation), B: Mean observed AUC (area under the concentration-time curve) in mucositis and controls (error bars indicate standard deviation). C: Observed ratio of mean pharmacokinetic parameters and simulated $\mathrm{F}_{\mathrm{G}}$ (fraction of absorbed drug escaping gut 
wall metabolism) between mucositis and controls. NEWE: nested enzyme-within-enterocyte model, obs: observed, pred: predicted (Kovanda et al., 2017).

\subsubsection{Untreated coeliac disease: simvastatin}

Untreated coeliac disease is an autoimmune disease characterised by villous blunting and atrophy when untreated. The villous blunting, that is reported to be due to a reduction in enterocyte lifespan to around 0.25 days (Brigic et al., 2012), has also been shown to be associated with lower levels of CYP3A4 (Johnson et al., 2001, Lang et al., 1996). Moron, and co-workers (Moron et al., 2013), carried out a clinical trial investigating of the impact of untreated coeliac disease on oral simvastatin, lipid lowering agent, mainly metabolised by CYP3A4, BCS class II (poorly soluble, highly permeable) compound (Prueksaritanont et al., 2003, Jiang et al., 2012). The drug displayed a significant increase in $C_{\max }$ with a ratio of 2.42 and 2.19 in untreated coeliac disease as compared to healthy volunteers and treated coeliac patients, respectively (Figure 8A and 8B) (Moron et al., 2013).

As the reported mechanism was reduced enterocyte lifespan, predictions were carried out using the default NEWE model and NEWE model with CYP3A4 gradient to test both assumptions. The NEWE model with CYP3A4 gradient predicted approximately $40 \%$ reduction in enzyme abundance per unit of enterocyte due to the reduced enterocyte lifespan (Figure $8 \mathrm{C}$ and $8 \mathrm{D}$ ). $\mathrm{F}_{\mathrm{G}}$ predictions also incorporated changes in the villous blood flow, where a 1.5-fold increase have been reported (Alvarez et al., 1993). The default NEWE model predicted an $\mathrm{F}_{\mathrm{G}}$ ratio of 1.54 and the NEWE model with $\mathrm{CYP} 3 \mathrm{~A} 4$ gradient predicted an $\mathrm{F}_{\mathrm{G}}$ ratio of 2.37. The NEWE model with CYP3A4 gradient was therefore in closer 
agreement with the observed mean $\mathrm{C}_{\max }$ ratio of 2.19-2.42 (Figure 8B), suggesting that the CYP3A4 gradient was a more accurate physiological description of the gut wall. Here it is worth pointing out that $\mathrm{C}_{\max }$ was the only observed comparator and should not be seen as being directly reflective of $\mathrm{F}_{\mathrm{G}}$.
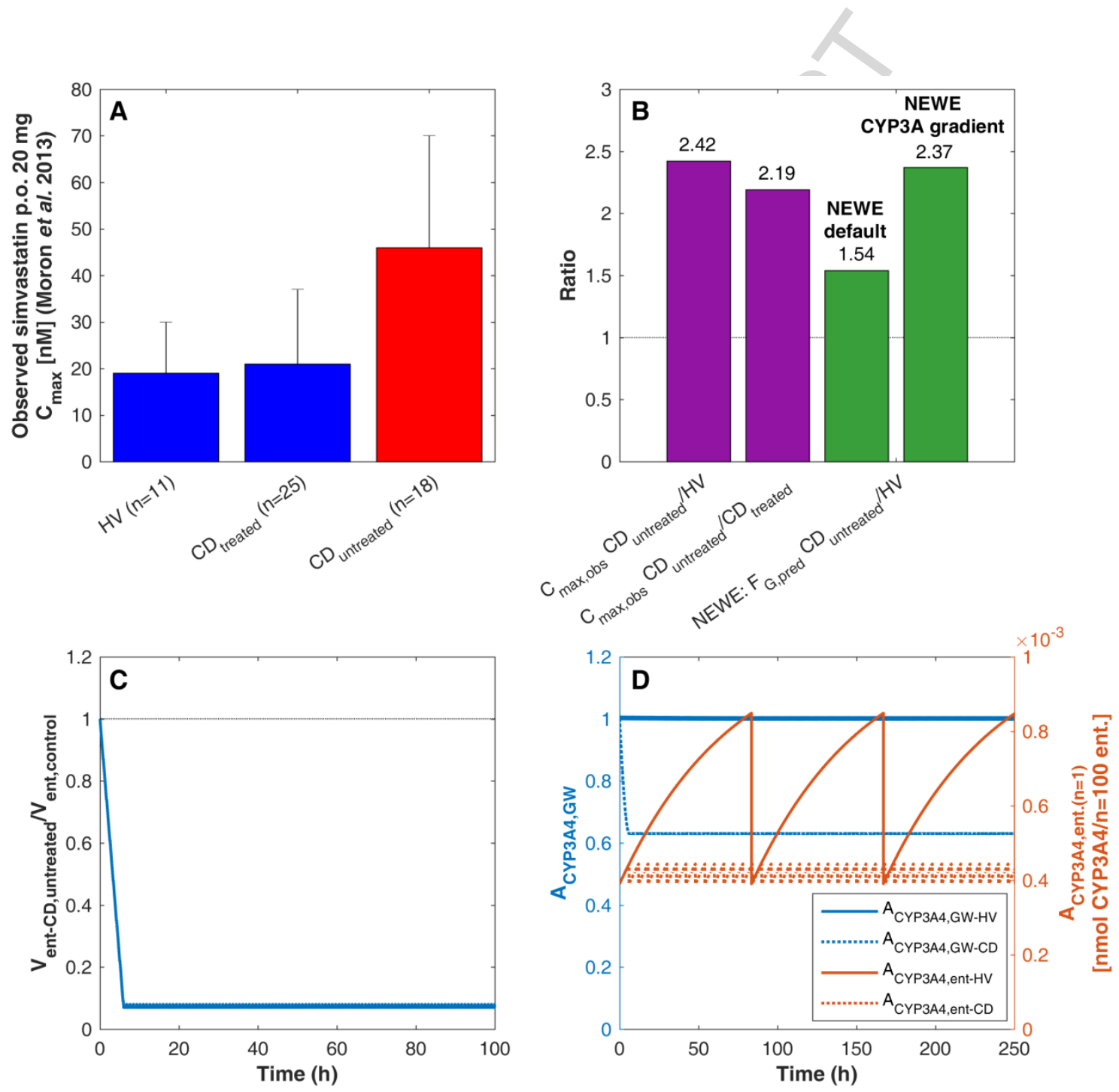

Figure 8. Observed and simulated impact of untreated coeliac disease on oral simvastatin exposure. A: Mean observed $\mathrm{C}_{\max }$ (maximum concentration) in healthy volunteers (HV) treated and untreated coeliac disease (CD; error bars indicate standard deviation), $\mathbf{B}$ : Observed ratios of pharmacokinetic parameters and simulated $\mathrm{F}_{\mathrm{G}}$ (fraction of absorbed drug escaping gut wall metabolism) ratio between CD and controls NEWE: nested enzyme-within- 
enterocyte model. C: Simulated relative enterocyte volume in untreated coeliac disease as compared to controls ( $\left.\mathrm{V}_{\text {ent,CD-untreated }} / \mathrm{V}_{\text {ent,control }}\right)$ where enterocyte turnover is perturbed to the disease state at time $=0 \mathrm{~h}$ and the new steady state volume is reached at around $7 \mathrm{~h}$ following disease induced turnover change, D: Simulated change in CYP3A4 at the level of total gut wall $(\mathrm{GW})$ due to change in enterocyte volume and at the level of a single enterocyte (ent) given the assumption of CYP3A4 maturation along the crypt-villous axis. obs: observed, pred: predicted (Moron et al., 2013).

Theoretical simulations were carried out to examine the impact of altered enterocyte lifespan (Figure 9A) and rate of enterocyte mitosis (Figure 9C) on $\mathrm{F}_{\mathrm{G}}$ for high to low $\mathrm{F}_{\mathrm{G}}$ compounds. The impact of reducing the enterocyte lifespan and mitosis rate were comparable where the low $\mathrm{F}_{\mathrm{G}}$ compounds displayed higher $\mathrm{F}_{\mathrm{G}}$ ratios in disease versus controls, as compared to higher $\mathrm{F}_{\mathrm{G}}$ compounds. The impact of altering enterocyte lifespan was slightly more pronounced as compared to changing the mitosis rate. 

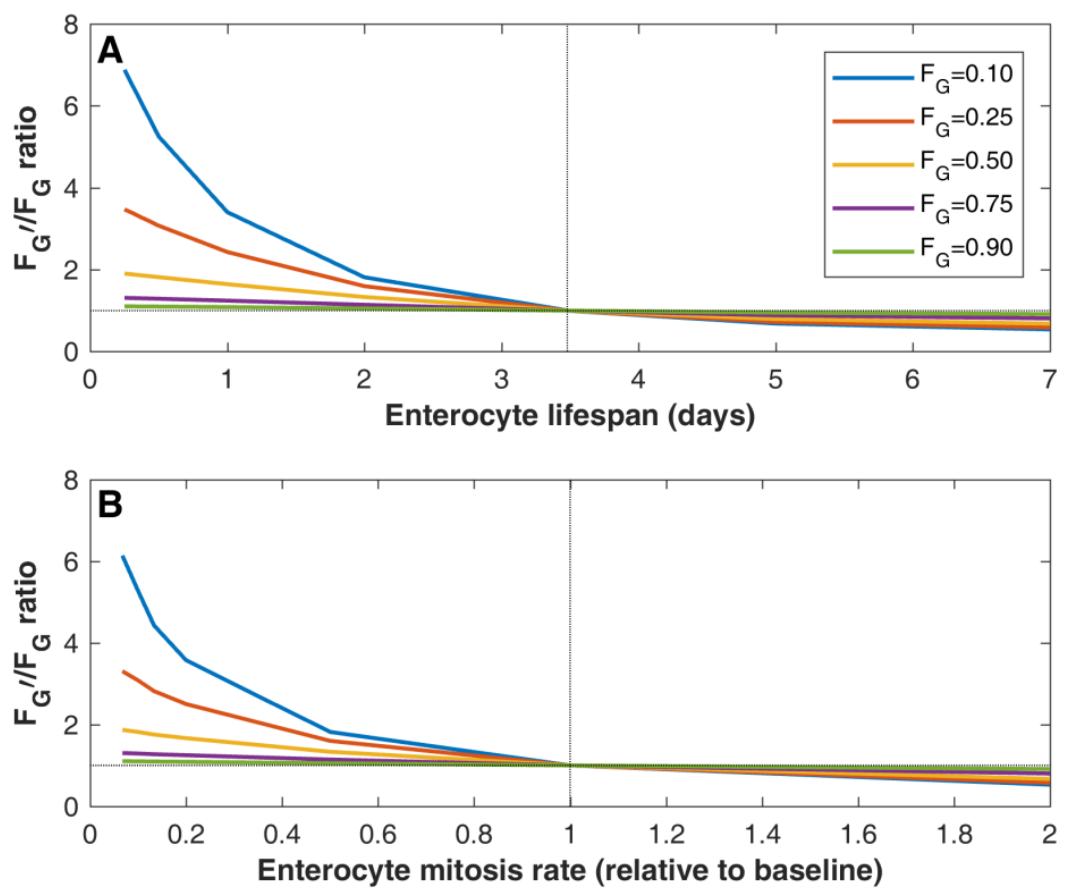

Figure 9. Theoretical impact of gut disease on $F_{G}$. Simulated $F_{G}$ ratio $\left(F_{G}{ }^{\prime} / F_{G}\right)$ at varying baseline $F_{G}$ values in healthy controls following changes in $\mathbf{A}$ : enterocyte lifespan and $\mathbf{B}$ : enterocyte mitosis rate. $\mathrm{F}_{\mathrm{G}}$ : fraction of absorbed drug that escapes gut wall metabolism.

\section{Discussion}

Here we report on the development and assessment of a novel PBPK model that describes the nested enzyme and enterocyte turnover in the gut wall. The NEWE model incorporated systems features to describe the population of enterocytes, and therefore represents a relatively unique approach to coupling pharmacokinetic and systems modelling. Two scenarios were investigated using the NEWE model, these were the prediction of $F_{G}$ following MBI and following gut disease. The outcome of these simulation studies are discussed below. 


\subsection{Mechanism-based inhibition}

The NEWE model gave a reasonably accurate description of recovery in enzyme activity following MBI by grapefruit juice based on enterocyte and enzyme turnover data informed by in vitro/in vivo experiments (Darwich et al., 2014, Yang et al., 2008). This suggests that the separation of enterocyte and enzyme turnover may successfully allow these parameters to become observable systems parameters rather than lumped drug-dependent parameters that are indirectly informed via clinical data. Turnover data is however rarely measured directly clinically or in human in vitro cell lines giving uncertainty to the mean turnover and its variability in the population. Examining the objective function space for the turnover parameters in the default NEWE model and NEWE model with a crypt-villous CYP3A4 gradient suggested that the latter is perhaps a more accurate description of physiology. Although the crypt-villous CYP3A4 gradient has been observed in vivo it is rarely considered in PBPK M\&S and little quantitative data has been published to enable an accurate description of this (Johnson et al., 2001, Kolars et al., 1992). Here the implementation of such a gradient should be seen as an illustrative example rather than an accurate description of the true CYP3A4 gradient along the crypt-villous axis. The CYP3A4 gradient did however appear to play a minor role in determining the extent of MBI.

The default NEWE model made little or no impact on the prediction of MBI as compared to the conventional well-stirred gut wall model. However, the inclusion of a drug-specific accessibility gradient in the gut lumen was shown to reduce the impact of MBI, suggesting it as a potential solution for improving on MBI predictions in the gut wall. Further simulations showed that this effect is pronounced for low $\mathrm{F}_{\mathrm{G}}$ substrate drugs in combination with potent mechanism-based inhibitors (high $\mathrm{k}_{\text {inact }}$, low $\mathrm{K}_{\mathrm{I}, \mathrm{u}}$ ), where up to $50 \%$ reduction in $\mathrm{F}_{\mathrm{G}}$ ratio 
following MBI was seen compared to the conventional enterocyte model. Little impact was seen on the overall predicted AUC ratio following MBI, this potentially because a static model was used to estimate the hepatic effect of the DDI as the gut wall was the main focus of this study.

In a simulation study by Chen, and co-workers (Chen et al., 2014), an accessibility constant and CYP3A4 gradient were studied in the context of MBI predictions. The conclusions were similar to here, where accessibility was shown to have the biggest impact on reducing the extent of MBI. However, in order to accurately consider both accessibility and a CYP3A4 crypt-villous gradient the approach given here provides a more physiologically accurate description as it considers the CYP3A4 gradient as a consequence of non-steady state enzyme kinetics where enzyme formation exceeds degradation rather than considering two wellstirred enterocyte regions with differing enzyme abundance and equal turnover, thus violating the most plausible mechanism for this gradient. In any case, it remains questionable whether the use of an accessibility constant or gradient is a reflection of the true mechanism that causes a reduction interaction between substrate and inhibitor. In theory this could equally be described by differing absorption windows between substrate and inhibitor along the length of the small intestine.

Considering the added complexity of the NEWE model, we believe that it does not provide an attractive solution for improving upon the prediction of MBI in healthy subjects. Rather we would suggest that dissolution and absorption effects may be a more viable explanation for the disparity between observed and predicted MBI. Many of these processes were ignored here, including the regional abundance of CYP3A4 and potential difference in spatial 
absorption windows between perpetrator and victim drugs. The lack of these features will likely impact the performance of the DDI simulations described herein and may be of interest to study in an extension of the nested turnover model.

The added consideration of the physiological mechanism of enzyme and cell turnover of the NEWE model may however provide scope for extrapolation to pathophysiological conditions where disease-drug interactions become relevant and by extension drug-drug interactions in disease. Discussion on gut disease follows.

\subsection{Gut disease}

The NEWE model was used to examine the ability to extrapolate intestinal extraction to gut disease based on observed enterocyte turnover data, where the hypothesis was that the altered oral drug exposure was a consequence reduced enzyme abundance due to perturbed enterocyte turnover/lifespan. Predicted $\mathrm{F}_{\mathrm{G}}$ ratios in disease using NEWE model, and NEWE model with CYP3A4 gradient, were in general in good agreement with the reported clinical pharmacokinetic parameters ( $F_{\text {oral }}$, AUC and $\mathrm{C}_{\max }$ ). It is important to note that the clinical pharmacokinetic parameters are not directly reflecting changes in $\mathrm{F}_{\mathrm{G}}$ alone, this should therefore not be seen as direct evidence of quantitative performance but, perhaps more reasonably, a qualitative indicator of the usefulness of this approach. The results suggest that the use of surrogate biomarkers of enterocyte mitosis and apoptosis/shedding may provide a viable basis for extrapolating gut wall metabolism from healthy to disease. 
In the case of untreated coeliac disease, the NEWE model with CYP3A4 gradient corresponded more closely with the observed data, when comparing the simulated trend in $\mathrm{F}_{\mathrm{G}}$ to observed $\mathrm{C}_{\max }$. Again, indicating that this model assumption was a closer description of intestinal physiology. Measured CYP3A4 abundance data from the gut wall in untreated coeliac disease differed to some extent to the simulated levels, where Lang, and co-workers (Lang et al., 1996), reported activity to be approximately one third of that in treated coeliac disease. Johnson, and co-workers, reported CYP3A4 activity to about $16 \%$ in untreated paediatric coeliac disease patients compared to controls (Johnson et al., 2001). By comparison the NEWE model predicted CYP3A4 activity to be approximately $60 \%$ of control per unit of enterocytes. This may a result of the sparse dataset that was used to inform the CYP3A4 gradient in the NEWE model, based on two villi in one individual only (Kolars et al., 1992). The enzyme activity data in coeliac disease suggest that the actual gradient in the overall population may be considerably steeper. Further, the use of pathophysiological data to inform the alteration in enterocyte turnover may be flawed as these experiments were not carried out with the intention of quantitatively describing enterocyte turnover but rather as qualitative biomarkers of disease. The use of this type of pathophysiological data has not been sufficiently explored in the context of PBPK and systems modelling.

Although absolute enterocyte turnover measurements are rarely carried out, surrogate biomarkers of enterocyte mitosis, apoptosis and shedding are routinely measured in the literature. The ability to use these surrogate biomarkers to inform gut wall enzyme abundances in special disease populations, using models such as the NEWE, would provide added benefit over proteomic data analysis. However, further work is needed to validate these within a quantitative PBPK systems modelling framework. 


\subsection{Further considerations}

In this simulation study we focused on gut wall metabolism alone and did therefore not consider the absorption process or drug disposition in great detail. The impact of enterocyte turnover on absorption therefore remains unexplored. This may be of some importance for drugs formulated as nanodelivery systems that may become trapped in the brushborder membrane of the enterocytes (Ensign et al., 2012). For these formulations, enterocyte turnover may act as a pre-systemic elimination pathway. Most likely this effect will be negligible in the healthy gut where enterocyte lifespan exceeds the absorption time but may become increasing importance in gut disease characterised by villous blunting. Further, we did not consider inter-individual variability in enterocyte lifespan or enzyme turnover. Previous work suggests that enterocyte turnover may vary considerably across the population (Darwich et al., 2014), the same may be true for enzyme turnover and expression along the crypt-villous axis (Kolars et al., 1992). Another simplification worth noting is that the enterocyte volume module was implemented outside the NEWE model and executed prior to NEWE simulations to inform input parameters for enterocyte volume and enzyme abundance.

When intracellular gut wall components become the target for treatment through interaction with the drug, then the ability to understand and design suitable dosage regimens may be directly linked to the understanding of the turnover of these targets and their host cellular tissue. 
The principle of coupling systems cell modelling with PBPK M\&S, as illustrated here, may be further extended to other tissues where cell turnover occurs at a fast enough rate to affect drug disposition, such as drug accumulation in/release from phagocytes/monocytes (Carlander et al., 2016), erythrocytes (Angelis-Stoforidis et al., 1999), as well as other endogenous cell populations and proteins. The added advantage would be to enable the use of measurable turnover data to break parameter identifiability for drug release or accumulation in physiological tissues, cell populations and more. The relative ease of implementation of such a model and the increase in computational power means that cell population-based systems models are becoming increasingly viable options for coupling with whole-body PBPK models.

A major hurdle to implementing the cell systems models is around the quality and interpretation of pathophysiological turnover data from the literature. Currently, this data is not being generated with the purpose of informing systems modelling but as qualitative biomarkers of gut disease. It is therefore likely that further work is needed to optimize the measurements of pathophysiological data with the specific aim of informing quantitative conclusions.

\section{Conclusions}

Here we presented a novel systems model for considering the nested enzyme turnover within the enterocytes coupled with a PBPK model of the gut wall. Although the model complexity 
compared to the added benefit meant that this model may not be attractive for modelling of mechanism-based inhibition in the gut wall, the models of gut disease indicated a potential for predicting the changes in gut wall metabolism in disease. The principles used here may find application in modelling of other cell populations to inform accumulation and release of drug to systemic circulation.

\section{Acknowledgements}

This research did not receive any specific grant from funding agencies in the public, commercial, or not-for-profit sectors.

\section{References}

Agoram, B., Woltosz, W. S. \& Bolger, M. B. 2001. Predicting the impact of physiological and biochemical processes on oral drug bioavailability. Adv Drug Deliv Rev, 50 Suppl 1, S41-67.

Alvarez, D., Vazquez, H., Bai, J. C., Mastai, R., Flores, D. \& Boerr, L. 1993. Superior mesenteric artery blood flow in celiac disease. Dig Dis Sci, 38, 1175-82.

Angelis-Stoforidis, P., Vajda, F. J. \& Christophidis, N. 1999. Methotrexate polyglutamate levels in circulating erythrocytes and polymorphs correlate with clinical efficacy in rheumatoid arthritis. Clin Exp Rheumatol, 17, 313-20.

Bhattacharya, S., Shoda, L. K., Zhang, Q., Woods, C. G., Howell, B. A., Siler, S. Q., Woodhead, J. L., Yang, Y., McMullen, P., Watkins, P. B. \& Andersen, M. E. 2012. Modeling drug- and chemical-induced hepatotoxicity with systems biology approaches. Front Physiol, 3, 462. 
Brigic, E., Hadzic, D. \& Mladina, N. 2012. Early and correct diagnosis of celiac disease in the prevention of growth disorders and child development. Mater Sociomed, 24, 2427.

Brown, R. P., Delp, M. D., Lindstedt, S. L., Rhomberg, L. R. \& Beliles, R. P. 1997. Physiological parameter values for physiologically based pharmacokinetic models. Toxicol Ind Health, 13, 407-84.

Burt, H. J., Pertinez, H., Sall, C., Collins, C., Hyland, R., Houston, J. B. \& Galetin, A. 2012. Progress curve mechanistic modeling approach for assessing time-dependent inhibition of CYP3A4. Drug Metab Dispos, 40, 1658-67.

Butterweck, V., Zdrojewski, I., Galloway, C., Frye, R. \& Derendorf, H. 2009. Toxicological and Pharmacokinetic Evaluation of Concomitant Intake of Grapefruit juice and Simvastatin in Rats after Repeated Treatment over 28 Days. Planta Medica, 75, 11961202.

Carlander, U., Li, D., Jolliet, O., Emond, C. \& Johanson, G. 2016. Toward a general physiologically-based pharmacokinetic model for intravenously injected nanoparticles. International journal of nanomedicine, 11, 625-40.

Certara 2018. Simcyp Simulator. 16 ed.

Chen, E. P., Tai, G. \& Ellens, H. 2014. The importance of villous physiology and morphology in mechanistic physiologically-based pharmacokinetic models. Pharm Res, 31, 305-21.

Darwich, A. S., Aslam, U., Ashcroft, D. M. \& Rostami-Hodjegan, A. 2014. Meta-analysis of the turnover of intestinal epithelia in preclinical animal species and humans. Drug Metab Dispos, 42, 2016-22.

Darwich, A. S., Neuhoff, S., Jamei, M. \& Rostami-Hodjegan, A. 2010. Interplay of metabolism and transport in determining oral drug absorption and gut wall 
metabolism: a simulation assessment using the "advanced dissolution, absorption, metabolism (ADAM)" model. Curr Drug Metab, 11, 716-29.

De Castro, W. V., Mertens-Talcott, S., Derendorf, H. \& Butterweck, V. 2007. Grapefruit juice-drug interactions: Grapefruit juice and its components inhibit p-glycoprotein (ABCB1) mediated transport of talinolol in caco-2 cells. Journal of Pharmaceutical Sciences, 96, 2808-2817.

Derendorf, H. \& Meibohm, B. 1999. Modeling of pharmacokinetic/pharmacodynamic (PK/PD) relationships: Concepts and perspectives. Pharmaceutical Research, 16, 176-185.

Duncan, M. \& Grant, G. 2003. Oral and intestinal mucositis - causes and possible treatments. Aliment Pharmacol Ther, 18, 853-74.

Ensign, L. M., Cone, R. \& Hanes, J. 2012. Oral drug delivery with polymeric nanoparticles: the gastrointestinal mucus barriers. Adv Drug Deliv Rev, 64, 557-70.

Fahmi, O. A., Hurst, S., Plowchalk, D., Cook, J., Guo, F., Youdim, K., Dickins, M., Phipps, A., Darekar, A., Hyland, R. \& Obach, R. S. 2009. Comparison of different algorithms for predicting clinical drug-drug interactions, based on the use of CYP3A4 in vitro data: predictions of compounds as precipitants of interaction. Drug Metab Dispos, 37, 1658-66.

Falci, D. R. \& Pasqualotto, A. C. 2013. Profile of isavuconazole and its potential in the treatment of severe invasive fungal infections. Infection and drug resistance, 6, $163-$ 74.

Freeman, D. J. 1991. Pharmacology and pharmacokinetics of cyclosporine. Clinical biochemistry, 24, 9-14. 
Galetin, A., Gertz, M. \& Houston, J. B. 2008. Potential role of intestinal first-pass metabolism in the prediction of drug-drug interactions. Expert Opin Drug Metab Toxicol, 4, 909-22.

Gertz, M., Davis, J. D., Harrison, A., Houston, J. B. \& Galetin, A. 2008. Grapefruit juicedrug interaction studies as a method to assess the extent of intestinal availability: utility and limitations. Curr Drug Metab, 9, 785-95.

Gertz, M., Harrison, A., Houston, J. B. \& Galetin, A. 2010. Prediction of human intestinal first-pass metabolism of 25 CYP3A substrates from in vitro clearance and permeability data. Drug Metab Dispos, 38, 1147-58.

Gertz, M., Houston, J. B. \& Galetin, A. 2011. Physiologically based pharmacokinetic modeling of intestinal first-pass metabolism of CYP3A substrates with high intestinal extraction. Drug Metab Dispos, 39, 1633-42.

Ghadi, R. \& Dand, N. 2017. BCS class IV drugs: Highly notorious candidates for formulation development. Journal of controlled release : official journal of the Controlled Release Society, 248, 71-95.

Gonzalez, D., Conrado, D. J., Theuretzbacher, U. \& Derendorf, H. 2011. The Effect of Critical Illness on Drug Distribution. Current Pharmaceutical Biotechnology, 12, 2030-2036.

Gonzalez, D., Schmidt, S. \& Derendorf, H. 2013. Importance of Relating Efficacy Measures to Unbound Drug Concentrations for Anti-Infective Agents. Clinical Microbiology Reviews, 26, 274-288.

Greenblatt, D. J. \& Derendorf, H. 2013. Grapefruit-medication interactions. Canadian Medical Association Journal, 185, 507-507.

Greenblatt, D. J., von Moltke, L. L., Harmatz, J. S., Chen, G., Weemhoff, J. L., Jen, C., Kelley, C. J., LeDuc, B. W. \& Zinny, M. A. 2003. Time course of recovery of 
cytochrome p450 3A function after single doses of grapefruit juice. Clin Pharmacol Ther, 74, 121-9.

Howgate, E. M., Rowland Yeo, K., Proctor, N. J., Tucker, G. T. \& Rostami-Hodjegan, A. 2006. Prediction of in vivo drug clearance from in vitro data. I: impact of interindividual variability. Xenobiotica, 36, 473-97.

Jamei, M. 2016. Recent Advances in Development and Application of Physiologically-Based Pharmacokinetic (PBPK) Models: a Transition from Academic Curiosity to Regulatory Acceptance. Curr Pharmacol Rep, 2, 161-169.

Jiang, T., Han, N., Zhao, B., Xie, Y. \& Wang, S. 2012. Enhanced dissolution rate and oral bioavailability of simvastatin nanocrystal prepared by sonoprecipitation. Drug development and industrial pharmacy, 38, 1230-9.

Johnson, T. N., Boussery, K., Rowland-Yeo, K., Tucker, G. T. \& Rostami-Hodjegan, A. 2010. A semi-mechanistic model to predict the effects of liver cirrhosis on drug clearance. Clin Pharmacokinet, 49, 189-206.

Johnson, T. N., Tanner, M. S., Taylor, C. J. \& Tucker, G. T. 2001. Enterocytic CYP3A4 in a paediatric population: developmental changes and the effect of coeliac disease and cystic fibrosis. Br J Clin Pharmacol, 51, 451-60.

Keefe, D. M., Brealey, J., Goland, G. J. \& Cummins, A. G. 2000. Chemotherapy for cancer causes apoptosis that precedes hypoplasia in crypts of the small intestine in humans. Gut, 47, 632-7.

Kolars, J. C., Awni, W. M., Merion, R. M. \& Watkins, P. B. 1991. First-pass metabolism of cyclosporin by the gut. Lancet, 338, 1488-90.

Kolars, J. C., Schmiedlin-Ren, P., Schuetz, J. D., Fang, C. \& Watkins, P. B. 1992. Identification of rifampin-inducible P450IIIA4 (CYP3A4) in human small bowel enterocytes. J Clin Invest, 90, 1871-8. 
Kovanda, L. L., Marty, F. M., Maertens, J., Desai, A. V., Lademacher, C., Engelhardt, M., Lu, Q. \& Hope, W. W. 2017. Impact of Mucositis on Absorption and Systemic Drug Exposure of Isavuconazole. Antimicrobial agents and chemotherapy, 61.

Lang, C. C., Brown, R. M., Kinirons, M. T., Deathridge, M. A., Guengerich, F. P., Kelleher, D., O'Briain, D. S., Ghishan, F. K. \& Wood, A. J. 1996. Decreased intestinal CYP3A in celiac disease: reversal after successful gluten-free diet: a potential source of interindividual variability in first-pass drug metabolism. Clin Pharmacol Ther, 59, 416.

Lundahl, J., Regardh, C. G., Edgar, B. \& Johnsson, G. 1995. Relationship between time of intake of grapefruit juice and its effect on pharmacokinetics and pharmacodynamics of felodipine in healthy subjects. Eur J Clin Pharmacol, 49, 61-7.

Margolskee, A., Darwich, A. S., Pepin, X., Aarons, L., Galetin, A., Rostami-Hodjegan, A., Carlert, S., Hammarberg, M., Hilgendorf, C., Johansson, P., Karlsson, E., Murphy, D., Tannergren, C., Thorn, H., Yasin, M., Mazuir, F., Nicolas, O., Ramusovic, S., Xu, C., Pathak, S. M., Korjamo, T., Laru, J., Malkki, J., Pappinen, S., Tuunainen, J., Dressman, J., Hansmann, S., Kostewicz, E., He, H., Heimbach, T., Wu, F., Hoft, C., Laplanche, L., Pang, Y., Bolger, M. B., Huehn, E., Lukacova, V., Mullin, J. M., Szeto, K. X., Costales, C., Lin, J., McAllister, M., Modi, S., Rotter, C., Varma, M., Wong, M., Mitra, A., Bevernage, J., Biewenga, J., Van Peer, A., Lloyd, R., Shardlow, C., Langguth, P., Mishenzon, I., Nguyen, M. A., Brown, J., Lennernas, H. \& Abrahamsson, B. 2017. IMI - Oral biopharmaceutics tools project - Evaluation of bottom-up PBPK prediction success part 2: An introduction to the simulation exercise and overview of results. Eur J Pharm Sci, 96, 610-625.

Moron, B., Verma, A. K., Das, P., Taavela, J., Dafik, L., Diraimondo, T. R., Albertelli, M. A., Kraemer, T., Maki, M., Khosla, C., Rogler, G. \& Makharia, G. K. 2013. CYP3A4- 
catalyzed simvastatin metabolism as a non-invasive marker of small intestinal health in celiac disease. Am J Gastroenterol, 108, 1344-51.

Obach, R. S., Walsky, R. L. \& Venkatakrishnan, K. 2007. Mechanism-based inactivation of human cytochrome p450 enzymes and the prediction of drug-drug interactions. Drug Metab Dispos, 35, 246-55.

Olivares-Morales, A., Ghosh, A., Aarons, L. \& Rostami-Hodjegan, A. 2016. Development of a Novel Simplified PBPK Absorption Model to Explain the Higher Relative Bioavailability of the OROS(R) Formulation of Oxybutynin. AAPS J, 18, 1532-1549.

Oliver, R. E., Jones, A. F. \& Rowland, M. 1998. What surface of the intestinal epithelium is effectively available to permeating drugs? J Pharm Sci, 87, 634-9.

Pang, K. S. 2003. Modeling of intestinal drug absorption: roles of transporters and metabolic enzymes (for the Gillette Review Series). Drug Metab Dispos, 31, 1507-19.

Prueksaritanont, T., Ma, B. \& Yu, N. 2003. The human hepatic metabolism of simvastatin hydroxy acid is mediated primarily by CYP3A, and not CYP2D6. British journal of clinical pharmacology, 56, 120-4.

Rowland Yeo, K., Walsky, R. L., Jamei, M., Rostami-Hodjegan, A. \& Tucker, G. T. 2011. Prediction of time-dependent CYP3A4 drug-drug interactions by physiologically based pharmacokinetic modelling: impact of inactivation parameters and enzyme turnover. Eur J Pharm Sci, 43, 160-73.

Schmitt-Hoffmann, A., Roos, B., Maares, J., Heep, M., Spickerman, J., Weidekamm, E., Brown, T. \& Roehrle, M. 2006. Multiple-dose pharmacokinetics and safety of the new antifungal triazole BAL4815 after intravenous infusion and oral administration of its prodrug, BAL8557, in healthy volunteers. Antimicrobial agents and chemotherapy, 50, 286-93. 
Schultz, K. R., Nevill, T. J., Balshaw, R. F., Toze, C. L., Corr, T., Currie, C. J., Strong, D. K. \& Keown, P. A. 2000. Effect of gastrointestinal inflammation and age on the pharmacokinetics of oral microemulsion cyclosporin $\mathrm{A}$ in the first month after bone marrow transplantation. Bone marrow transplantation, 26, 545-51.

Shalimar, Das, P., Sreenivas, V., Gupta, S. D., Panda, S. K. \& Makharia, G. K. 2013. Mechanism of villus atrophy in celiac disease - role of apoptosis and epithelial regeneration. Arch Pathol Lab Med, 137, 1262-1269.

Smecuol, E., Bai, J. C., Vazquez, H., Kogan, Z., Cabanne, A., Niveloni, S., Pedreira, S., Boerr, L., Maurino, E. \& Meddings, J. B. 1997. Gastrointestinal permeability in celiac disease. Gastroenterology, 112, 1129-36.

Sugano, K. 2009. Theoretical investigation of passive intestinal membrane permeability using Monte Carlo method to generate drug-like molecule population. Int J Pharm, 373, 5561.

Takanaga, H., Ohnishi, A., Murakami, H., Matsuo, H., Higuchi, S., Urae, A., Irie, S., Furuie, H., Matsukuma, K., Kimura, M., Kawano, K., Orii, Y., Tanaka, T. \& Sawada, Y. 2000. Relationship between time after intake of grapefruit juice and the effect on pharmacokinetics and pharmacodynamics of nisoldipine in healthy subjects. Clin Pharmacol Ther, 67, 201-14.

Thelen, K. \& Dressman, J. B. 2009. Cytochrome P450-mediated metabolism in the human gut wall. J Pharm Pharmacol, 61, 541-58.

Thiele, I., Clancy, C. M., Heinken, A. \& Fleming, R. M. T. 2017. Quantitative systems pharmacology and the personalized drug-microbiota-diet axis. Current Opinion in Systems Biology, 4, 43-52.

Townsend, R., Kato, K., Hale, C., Kowalski, D., Lademacher, C., Yamazaki, T., Akhtar, S. \& Desai, A. 2018. Two Phase 1, Open-Label, Mass Balance Studies to Determine the 
Pharmacokinetics of 14 C-Labeled Isavuconazonium Sulfate in Healthy Male Volunteers. Clinical pharmacology in drug development, 7, 207-216.

Yang, J., Jamei, M., Yeo, K. R., Tucker, G. T. \& Rostami-Hodjegan, A. 2007. Prediction of intestinal first-pass drug metabolism. Curr Drug Metab, 8, 676-84.

Yang, J., Liao, M., Shou, M., Jamei, M., Yeo, K. R., Tucker, G. T. \& Rostami-Hodjegan, A. 2008. Cytochrome p450 turnover: regulation of synthesis and degradation, methods for determining rates, and implications for the prediction of drug interactions. Curr Drug Metab, 9, 384-94.

Yu, L. X. \& Amidon, G. L. 1999. A compartmental absorption and transit model for estimating oral drug absorption. Int J Pharm, 186, 119-25.

Yu, L. X., Crison, J. R. \& Amidon, G. L. 1996. Compartmental transit and dispersion model analysis of small intestinal transit flow in humans. Int J Pharm, 140, 111-118.

Zhang, X., Quinney, S. K., Gorski, J. C., Jones, D. R. \& Hall, S. D. 2009.

Semiphysiologically based pharmacokinetic models for the inhibition of midazolam clearance by diltiazem and its major metabolite. Drug Metab Dispos, 37, 1587-97.

Zhou, S., Chan, E., Li, X. \& Huang, M. 2005. Clinical outcomes and management of mechanism-based inhibition of cytochrome P450 3A4. Ther Clin Risk Manag, 1, 313. 


\section{Graphical abstract}
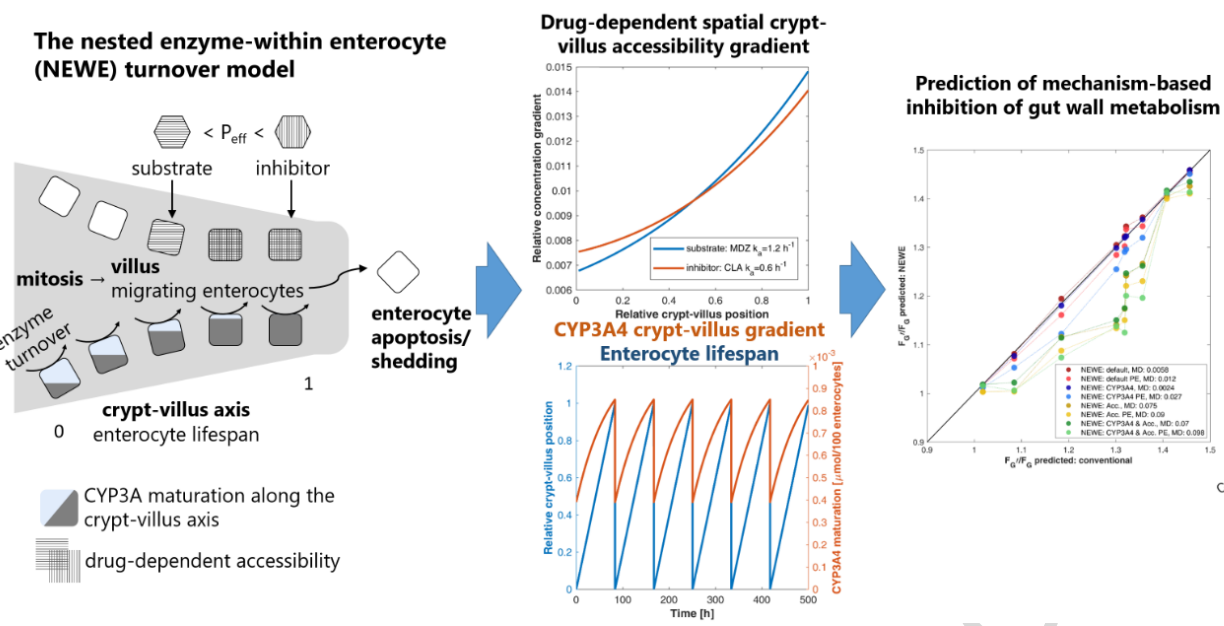

Prediction of gut disease effect on gut wall metabolism

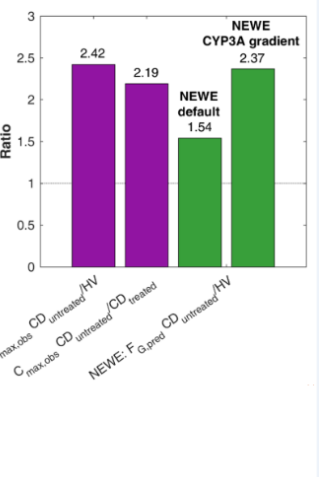

